\title{
Neurologic complications after the frozen elephant trunk procedure: A meta-analysis of more than 3000 patients
}

Ourania Preventza, MD, ${ }^{\mathrm{a}, \mathrm{b}}$ Jane L. Liao, MD, ${ }^{\mathrm{a}}$ Jacqueline K. Olive, BA, ${ }^{\mathrm{a}}$ Katherine Simpson, MS, Andre C. Critsinelis, MD, ${ }^{\mathrm{c}}$ Matt D. Price, MS, ${ }^{\mathrm{a}, \mathrm{d}}$ Marianne Galati, MSW, MLS, ${ }^{\mathrm{e}}$ Lorraine D. Cornwell, MD, ${ }^{\mathrm{a}, \mathrm{f}}$ Vicente Orozco-Sevilla, MD, ${ }^{\mathrm{a}, \mathrm{b}}$ Shuab Omer, MD, ${ }^{\mathrm{a}, \mathrm{f}}$ Ernesto Jimenez, MD, ${ }^{\mathrm{a}, \mathrm{f}}$ Scott A. LeMaire, MD, ${ }^{\mathrm{a}, \mathrm{b}, \mathrm{d}}$ and Joseph S. Coselli, $\mathrm{MD}^{\mathrm{a}, \mathrm{b}}$

\section{ABSTRACT}

Objective: The frozen elephant trunk technique's safety regarding spinal cord ischemia has been questioned. We used a meta-analysis to determine the rates of adverse neurologic events and mortality.

Methods: We searched PubMed/Medline, Embase, Scopus, and Cochrane databases (inception to April 2018) to identify studies of neurologic events after the frozen elephant trunk procedure. Separate meta-analyses were conducted with random-effects models to assess frozen elephant trunk associations with spinal cord ischemia, stroke, operative mortality, and all adverse events combined. Subgroup analyses compared outcomes in patients with acute versus nonacute type A dissection and aneurysm and with different extents of coverage.

Results: Thirty-five studies (total $\mathrm{N}=3154$ ) met inclusion criteria. The pooled rates of the outcomes of interest were $4.7 \%$ (95\% confidence interval, 3.5-6.2) for spinal cord ischemia, 7.6\% (95\% confidence interval, 5.0-11.5) for stroke, and $8.8 \%$ (95\% confidence interval, 7.0-10.9) for operative mortality. The spinal cord ischemia event rate was higher with stent length $15 \mathrm{~cm}$ or greater or coverage to $\mathrm{T} 8$ or beyond than with stent length of $10 \mathrm{~cm}(11.6 \%$ vs $2.5 \%, P<.001)$. Adverse event rates in patients with acute type A aortic dissection versus nonacute dissection or aneurysm were as follows: mortality $9.2 \%$ versus $7.6 \%(P=.46)$, stroke $9.3 \%$ versus $6.6 \%(P=.51)$, and overall adverse events $22.0 \%$ versus $16.5 \%(P=.41)$.

Conclusions: As the frozen elephant trunk procedure becomes more popular, accurate data regarding outcomes are vital. We associated the frozen elephant trunk technique with (nonsignificantly) more adverse events overall in acute type A dissection cases. Stent length of $10 \mathrm{~cm}$ was associated with significantly less risk of spinal cord ischemia. Using a stent $15 \mathrm{~cm}$ or greater or coverage extending to T8 or farther should be avoided. (J Thorac Cardiovasc Surg 2020;160:20-33)

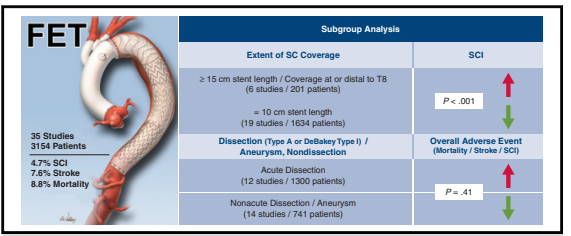

Visual summary of our meta-analysis of $35 \mathrm{FET}$ studies, with results and subgroup analyses.

\section{Central Message}

In FET, 10-cm stent length is advisable; length $15 \mathrm{~cm}$ or greater or coverage to or beyond $\mathrm{T} 8$ should be avoided to prevent SCI. FET should be used cautiously for acute type A aortic dissection.

\section{Perspective}

This meta-analysis of 35 observational studies examines mortality and neurologic outcomes associated with the FET technique in patients who require total arch replacement. Currently, the results represent the best available evidence regarding the outcomes of FET in such patients. Judicious use of the technique is advisable.

See Commentaries on pages 34 and 35.
Traditionally, the elephant trunk (ET) procedure involves 2 stages, and the likelihood of death before the second stage is high. ${ }^{1-6}$ The frozen elephant trunk (FET) procedure is a newer approach designed to treat extensive pathology of

From the ${ }^{\mathrm{a}}$ Division of Cardiothoracic Surgery; ${ }^{\mathrm{c}}$ Division of Cardiothoracic Transplantation and Circulatory Support; ${ }^{\mathrm{d}}$ Office of Surgical Research; Michael E. DeBakey Department of Surgery, Baylor College of Medicine, Houston, Tex; ${ }^{\mathrm{b}}$ Department of Cardiovascular Surgery, Texas Heart Institute, Houston, Tex; ${ }^{\mathrm{e}}$ Texas Medical Center Library, Houston, Tex; ${ }^{\mathrm{f}}$ Division of Cardiothoracic Surgery, Michael E. DeBakey Veterans Affairs Medical Center, Houston, Tex.

Dr Liao is a graduating medical student from the Indiana University School of Medicine, Indianapolis, Indiana.

Dr Orozco-Sevilla is currently with the Division of Cardiothoracic Surgery, Department of Surgery, University of Miami Miller School of Medicine, Miami, Florida. Read at the 99th Annual Meeting of The American Association for Thoracic Surgery, Toronto, Ontario, Canada, May 4-7, 2019. the thoracic aorta in a single stage or by facilitating the second stage of a 2-stage procedure. ${ }^{7}$ Single-center institutional experiences and small series comprise most of the existing reports. ${ }^{8}$

Received for publication May 7, 2019; revisions received Oct 10, 2019; accepted for publication Oct 11, 2019; available ahead of print Oct 17, 2019.

Address for reprints: Ourania Preventza, MD, Division of Cardiothoracic Surgery, Michael E. DeBakey Department of Surgery, Baylor College of Medicine, BCM 390, One Baylor Plaza, Houston, TX 77030 (E-mail: preventz@bcm.edu). 0022-5223

Copyright (c) 2019 by The American Association for Thoracic Surgery. Published by Elsevier Inc. This is an open access article under the CC BY-NC-ND license (http:// creativecommons.org/licenses/by-nc-nd/4.0/).

https://doi.org/10.1016/j.jtcvs.2019.10.031 

Abbreviations and Acronyms
$\mathrm{CI}=$ confidence interval
$\mathrm{ET}=$ elephant trunk
FET $=$ frozen elephant trunk
$\mathrm{SCI}=$ spinal cord ischemia

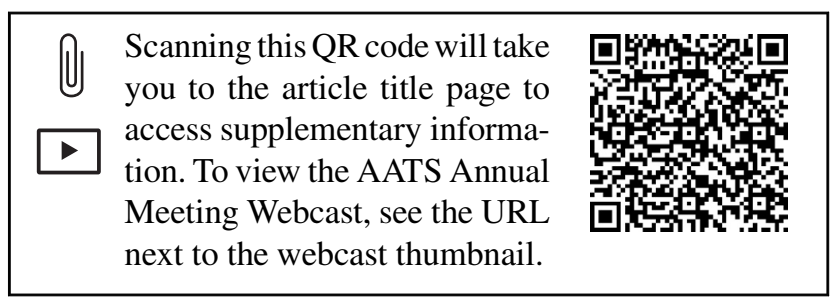

One of the main drawbacks of this newer approach is its potential association with neurologic events. Neurologic complications such as permanent stroke and spinal cord ischemia (SCI) are the most devastating complications of aortic surgery. The emotional and financial burdens for the patient, the patient's family, and the healthcare system are enormous and have lifelong implications. ${ }^{9}$ This metaanalysis examined the current evidence regarding mortality and neurologic complications, with special focus on SCI, associated with the use of the FET (Video 1).

\section{PATIENTS AND METHODS}

\section{Search Strategy}

Four databases (EMBASE, PubMed/Medline, Scopus, and Cochrane Library) were searched from their beginning to April 2018 to identify studies of the potential association between the FET approach and new postoperative neurologic symptoms (permanent or transient). The search terms used are listed in Table 1. Only English-language articles were searched. The references of all articles included in the study were examined for further relevant series.

\section{Study Design and Eligibility Criteria}

A study was deemed eligible if it described aortic arch procedures performed by the ET technique, either "frozen" or "stented." The definition of FET included a total arch operation. Proximal arch or hemiarch procedures (ie, procedures that did not involve the entire arch) with antegrade or retrograde stent delivery in the descending thoracic aorta were excluded from this analysis. Other inclusion criteria included a description of intrathoracic aortic arch repair performed via median sternotomy, the baseline characteristics of the patients, and the incidence of permanent or transient SCI, mortality, or permanent or transient stroke, as well as a sample size of 10 or more patients to prevent bias arising from small samples (Figure 1).

When multiple publications by the same authors were identified and study cohorts overlapped, only the latest report was included. Other meta-analysis studies were excluded, as were reports that describe only surgical techniques. Preferred Reporting Items for Systematic Review and Meta-Analysis guidelines were used. ${ }^{10}$

The abstracts of all articles were independently assessed by 2 reviewers (O.P. and J.S.C.); if the abstract suggested that the study met the inclusion criteria for our analysis, the full-text article was retrieved. Available data were analyzed, and if the 2 reviewers made different decisions about whether a given article should be included, a consensus was reached by reexamining the articles with regard to the exclusion and inclusion criteria and the specific techniques described. Data were extracted from abstracts, figures, and tables and entered into Microsoft Excel (Microsoft Corp, Redmond, Wash). In addition, attempts were made to contact the individual authors for any necessary clarifications.

\section{Statistical Analysis}

Standard descriptive statistics using meta-analysis software, which allowed us to account for the differing weights of the studies, were used to summarize the demographic, preoperative, intraoperative, and outcome data of the eligible studies. Data are presented as number and percentage or mean with $95 \%$ confidence interval (CI), as appropriate. The primary end points of the meta-analysis were stroke, SCI (reported as paralysis, paraplegia, or paraparesis), and operative mortality (within 30 days of surgery or before hospital discharge). The pooled effect estimates were calculated as the weighted mean by using a random-effects model (DerSimonian-Laird), which incorporates between-trial heterogeneity and gives wider and more conservative CIs when heterogeneity is present. ${ }^{11}$ The analyses were performed after a logit transformation of the data, and the results were expressed as an event rate $(\%)$ with a $95 \%$ CI.

Two subgroup analyses were performed, using the Z-test to obtain the $P$ value comparing the 2 groups. The first one compared outcomes from studies that included only patients with acute type A aortic dissection versus studies that included only patients with nonacute type A dissection and aneurysm to determine whether FET operations yielded different results in these 2 patient populations. The second subgroup analysis compared the results from studies that used only a longer stent $(\geq 15 \mathrm{~cm}$ or spinal cord coverage to T8 or farther) versus those that used only a shorter $(10-\mathrm{cm})$ stent.

The $\mathrm{I}^{2}$ statistic, defined as the percentage of total variability across studies attributable to heterogeneity rather than chance, was used to assess statistical heterogeneity. The $\mathrm{I}^{2}$ value lies between $0 \%$ and $100 \%$, and is presented with a $95 \% \mathrm{CI}$. We used published guidelines to classify the heterogeneity as low $\left(\mathrm{I}^{2}=25 \%\right.$ to $\left.49 \%\right)$, moderate $\left(\mathrm{I}^{2}=50 \%\right.$ to $\left.74 \%\right)$, or high $\left(\mathrm{I}^{2}>75 \%\right){ }^{12,13}$ In addition, the prediction interval was calculated to determine the range in which the true effect size would fall in $95 \%$ of all populations. The possibility of publication bias was evaluated quantitatively with the Egger test and assessed qualitatively with funnel plots. The funnel plots were constructed by Duval and Tweedie's "trim and fill" method, which offers a more nuanced perspective and estimates how the effect size would shift if the apparent bias were to be removed by imputing the missing studies. All statistical analyses were conducted with Comprehensive Meta-Analysis statistical software (version 3, Biostat Inc, Englewood, NJ).

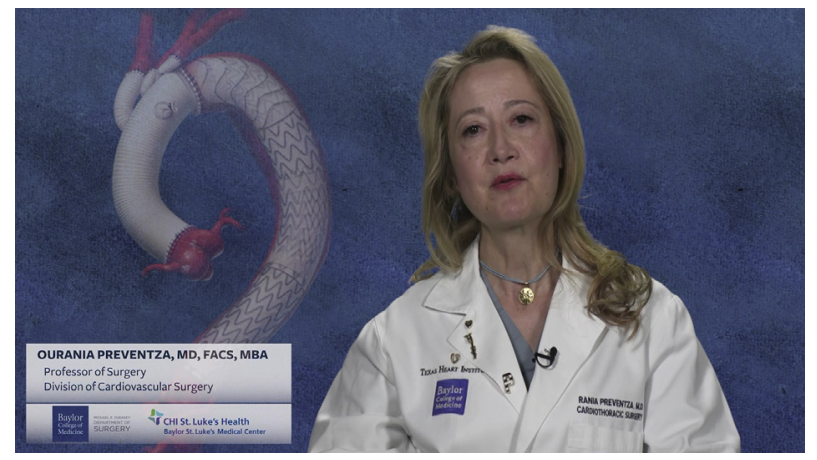

VIDEO 1. Summary of meta-analysis study of more than 3000 patients in whom the FET technique was used and a discussion of this technique's importance. Video available at: https://www.jtcvs.org/article/S00225223(19)32242-1/fulltext. 
TABLE 1. Search terms used to identify articles for review

\begin{tabular}{|c|c|}
\hline Database & Search terms \\
\hline PubMed/Medline & 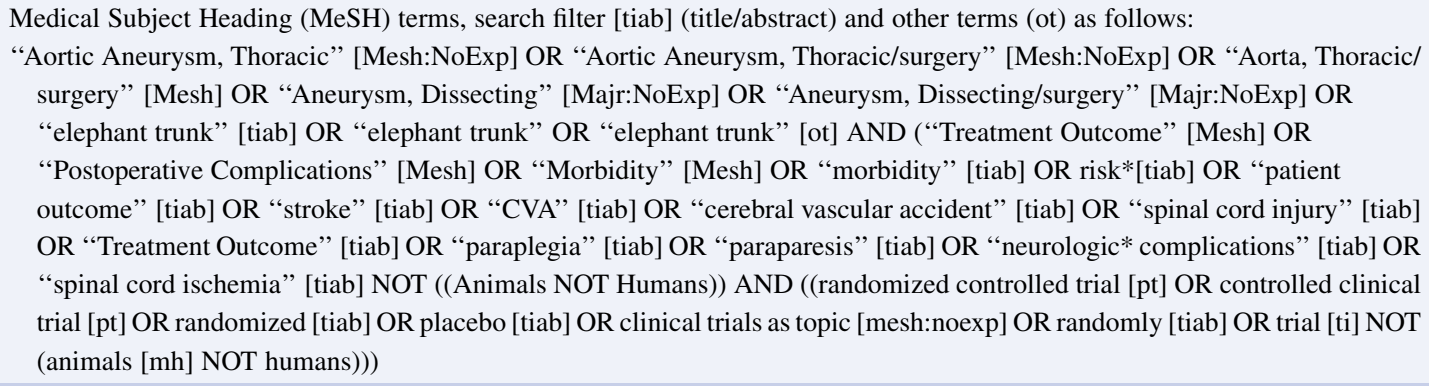 \\
\hline Scopus & $\begin{array}{l}\text { (TITLE-ABS-KEY ((Stroke OR “cerebral vascular accident” OR “CVA" OR “spinal cord injury" OR "spinal cord ischemia" } \\
\text { OR “paraplegia” OR "paraparesis" OR (neurologic* AND complication*)))) AND (TITLE-ABS-KEY ("elephant trunk" OR } \\
\text { (elephant AND trunk))) AND (LIMIT-TO (LANGUAGE, "English")) }\end{array}$ \\
\hline Embase & $\begin{array}{l}\text { 'cerebrovascular accident'/exp OR ‘spinal cord injury’/exp OR ‘spinal cord ischemia'/exp OR ‘paraplegia'/exp OR 'neurological } \\
\text { complication'/exp OR 'stroke' OR 'CVA' OR 'cerebral vascular accident' OR 'spinal cord injury' OR paraplegia OR } \\
\text { paraparesis OR 'neurologic* complications' OR (neurologic* AND complication*) OR 'spinal cord ischemia' 'elephant trunk } \\
\text { technique'/exp OR 'elephant trunk procedure'/exp OR (elephant AND trunk) OR 'elephant trunk':ab,ti OR 'elephant trunk' } \\
\text { AND [english] }\end{array}$ \\
\hline Cochrane Library & "elephant trunk" \\
\hline
\end{tabular}

\section{RESULTS}

\section{Study Selection and Characteristics of the Trials}

The search yielded 745 articles; 390 were excluded as duplicate or overlapping publications, and 355 were deemed potentially relevant. Another 320 articles were excluded after exclusion criteria were applied (Figure 1). Thus, our analysis included 34 publications that met the criteria for full review (Table 2). ${ }^{14-47}$ One of these publications ${ }^{25}$ reported on 2 separate cohorts, so we treated it as 2 studies for the purpose of our analyses. Thus, our effective sample size was 35 studies.

The included studies were published between 2002 and 2018, and involved a total of 3154 patients (2274 male, $73.6 \%$ [95\% CI, 70.6-76.4]) with a mean age of 55.3 years (95\% CI, 51.3-59.3) (Table 3). Emergency repair was reported in 33 studies and performed in 1705 patients $(53.2 \%)$. The mean hospital stay, which was reported in 9 studies, was 15.2 days (95\% CI, 14.5-15.83), and the mean follow-up period (based on 15 studies) was 30.4 months ( $95 \%$ CI, 24.3-36.4).

Various stents and devices were used: Jotec E-vita (Jotec GmbH, Hechingen, Germany), stainless steel Gianturco Z (Cook Group, Inc, Bloomington, Ind), Chavan-Haverich Prosthesis (Curative GmbH, Dresden, Germany), Cronus (MicroPort Medical Co, Ltd, Shanghai, China), Thoraflex Hybrid Prosthesis (Vascutek, Terumo, Inchinnan, Scotland, UK), and E-Vita Open and E-Vita Open Plus (Jotec GmbH, Hechingen, Germany). In addition, some investigators used custom-made FET devices with the addition of an intact or modified Gore TAG (WL Gore and Associates, Flagstaff, Ariz), Medtronic Valiant (Medtronic, Santa Rosa, Calif), or Cook endograft (Cook Group, Bloomington, Ind). Also, another custom-made stent was used that comprised a double-linked 10-bend $\mathrm{Z}$ stent sutured into an ultrathin woven Dacron graft. One series used a vascular graft (Yuhengjia Sci-Tech Co Ltd, Beijing, China) with the addition of a single-branch graft (Intervascular InterGard Knitted Graft; Datascope Co, Montvale, NJ).

\section{Neurologic Morbidity}

Clinical outcomes, including overall (ie, both permanent and transient) stroke and SCI, (paralysis, paraplegia, or paraparesis) are summarized in Table 4. The rate of overall stroke (temporary and permanent) ranged from $0 \%$ to $40.9 \%$, and the rate of any spinal cord adverse event ranged from $0 \%$ to $24.0 \%$. The pooled outcome rates $(95 \% \mathrm{CI})$ with corresponding results of heterogeneity and publication bias are shown in Table 5 .

The proportional meta-analysis for overall permanent or transient stroke as reported in 32 studies showed a pooled estimate of $7.6 \%$ (95\% CI, 5.0-11.5), albeit with high heterogeneity $\left(\mathrm{I}^{2}=88.3 \%\right.$ ) (Figure 2$)$. The prediction interval taking the heterogeneity into account indicated that $95 \%$ of the population would be within the range of $2.9 \%$ to $12.3 \%$. Publication bias was seen both qualitatively (asymmetry in the funnel plot, with missing studies to the right) and quantitatively (Egger $P=.003$ ) (Figure 3).

The pooled rate for overall SCI (paralysis, paraplegia, or paraparesis) was $4.7 \%(95 \%$ CI, 3.5-6.2), with $\mathrm{I}^{2}=46.3 \%$ indicating low heterogeneity (Figure 2). Taking this heterogeneity into account yielded a prediction interval of $2.8 \%$ to $6.6 \%$, which is the range into 


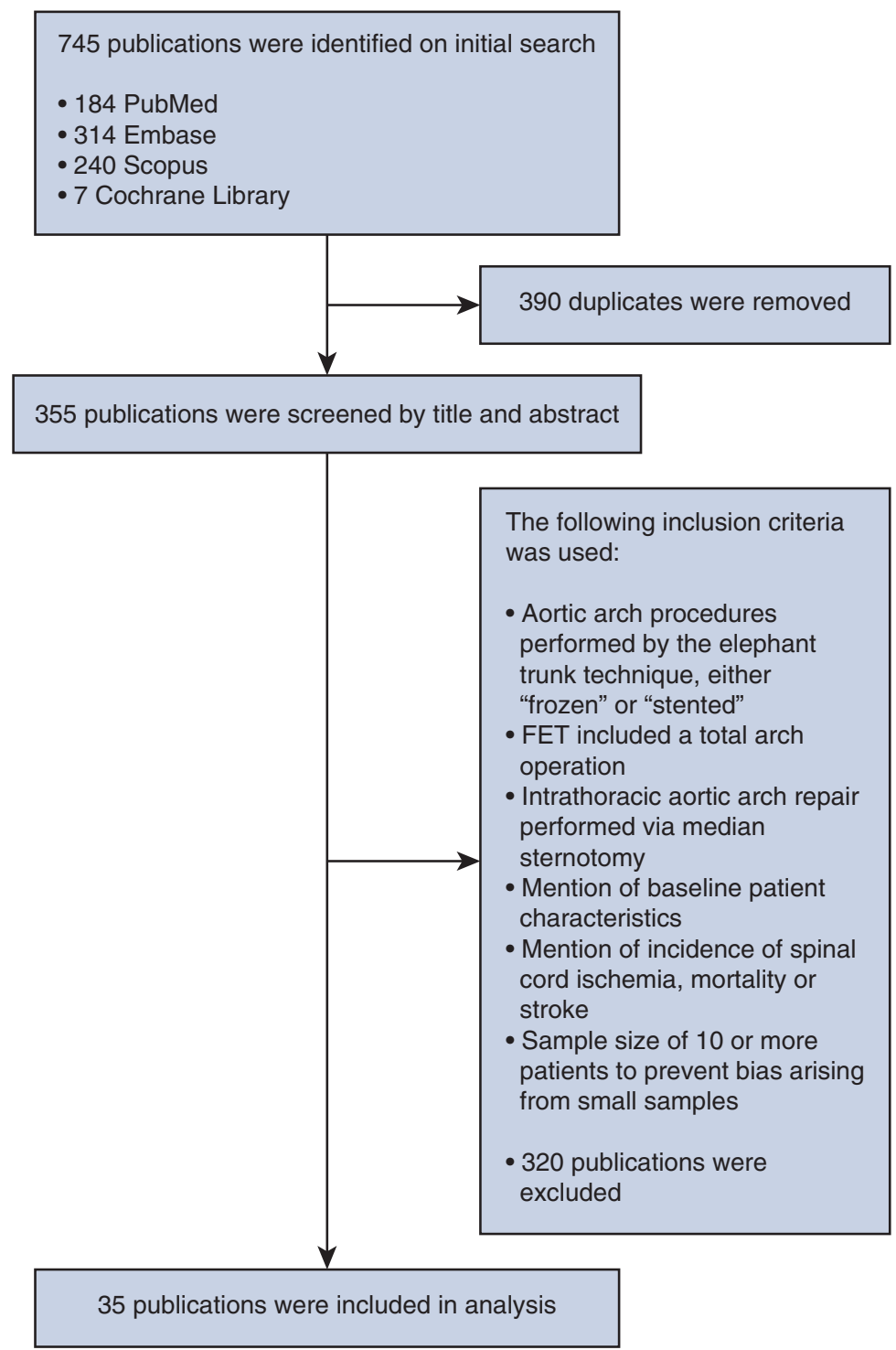

FIGURE 1. Flow chart showing selection and screening process for articles considered for inclusion in the meta-analysis. FET, Frozen elephant trunk.

which $95 \%$ of the population would have been. Publication bias was seen both qualitatively (asymmetry in the funnel plot, with missing studies to the right) and quantitatively (Egger $P=.008$ ) (Figure 3). All 35 articles reported SCI data.

\section{Operative Mortality}

The rate of operative mortality (variously reported as operative, 30-day, and in-hospital mortality) ranged from $0 \%$ to $21.6 \%$. One study did not report operative mortality specifically for $\mathrm{FET}^{26}$; for the remaining 34 studies, the total pooled operative mortality rate was $8.8 \%$ (95\% CI, 7.010.9) (Figure 2). The $\mathrm{I}^{2}=60.5 \%$ indicates moderate heterogeneity. The prediction interval taking the heterogeneity into account indicated that $95 \%$ of the population would be within the range of $6.4 \%$ to $11.2 \%$. Publication bias was seen both qualitatively (asymmetry in the funnel plot with missing studies to the right) and quantitatively (Egger $P=.002$ ) (Figure 3).

\section{Subgroup Analysis}

Spinal cord coverage $\mathrm{T} 8$ or beyond (or stent length $\geq 15 \mathrm{~cm}$ ) and spinal cord ischemia. We compared studies performed only in patients with spinal cord coverage T8 or beyond or $15 \mathrm{~cm}$ or greater stent length $(\mathrm{n}=6,201 \mathrm{pa}-$ tients), ${ }^{15,23,32-34,42}$ with studies performed only in patients with stent length equal to $10 \mathrm{~cm}(\mathrm{n}=19,1634 \mathrm{pa}-$ tients). ${ }^{15,17-19,21,22,24,25,27,28,33,35,37,40-42,45,46}$ The patients 
TABLE 2. Study characteristics

\begin{tabular}{|c|c|c|c|c|}
\hline First author (year) & Study period & $\mathbf{N}$ & Country & Institution \\
\hline Usui $(2002)^{14}$ & $1997-2002$ & 24 & Japan & $\begin{array}{l}\text { Nagoya University Graduate School of Medicine, Aichi } \\
\text { Medical University }\end{array}$ \\
\hline Flores $(2006)^{15}$ & $1996-2004$ & 25 & Japan & Hokkaido University Graduate School of Medicine \\
\hline Shimamura $(2008)^{16}$ & 1994-2004 & 126 & Japan & $\begin{array}{l}\text { Osaka University Graduate School of Medicine, Osaka } \\
\text { General Medical Center, Morinomiya Hospital }\end{array}$ \\
\hline $\operatorname{Li}(2009)^{17}$ & $2003-2008$ & 31 & China & $\begin{array}{l}\text { Cardiovascular Institute and Fu Wai Hospital, Chinese } \\
\text { Academy of Medical Sciences and Peking Union } \\
\text { Medical College }\end{array}$ \\
\hline Chen $(2010)^{18}$ & 2004-2009 & 28 & China & $\begin{array}{l}\text { Nanjing Cardiovascular Disease Research Institute, } \\
\text { Nainjing First Hospital Affiliated to Nanjing Medical } \\
\text { University }\end{array}$ \\
\hline Sun $(2010)^{19}$ & $2003-2008$ & 19 & China & $\begin{array}{l}\text { Cardiovascular Institute and Fu Wai Hospital, Peking } \\
\text { Union Medical College, Chinese Academy of Medical } \\
\text { Science, Tianjin Cardiovascular Institute and Tianjin } \\
\text { Chest Hospital }\end{array}$ \\
\hline Lima $(2012)^{20}$ & 2001-2010 & 31 & United States & Heart and Vascular Institute, Cleveland Clinic \\
\hline Shen $(2012)^{21}$ & 2010 & 38 & China & The Second Xiangya Hospital, Central South University \\
\hline Zhao $(2012)^{22}$ & $2006-2011$ & 24 & China & $\begin{array}{l}\text { Beijing Aortic Disease Center; Beijing Institute of Heart, } \\
\text { Lung and Blood Vessel Diseases; Beijing Anzhen } \\
\text { Hospital, Capital Medical University }\end{array}$ \\
\hline Hoffman $(2013)^{23}$ & $2009-2011$ & 32 & Germany & University Hospital RWTH Aachen \\
\hline Di Marco $(2014)^{24}$ & 2013-2014 & 11 & Italy & S. Orsola-Malpighi Hospital, University of Bologna \\
\hline $\operatorname{Ma}(2014)^{25 *}$ & 2003-2012 & 456 & China & Chinese multicenter $\dagger$ \\
\hline $\mathrm{Ma}(2014 \mathrm{~B})^{25 *}$ & 2003-2012 & 347 & China & Chinese multicenter $\dagger$ \\
\hline Nakamura $(2014)^{26}$ & $1998-2010$ & 51 & Japan & $\begin{array}{l}\text { University of Miyazaki, Miyazaki Prefectural Nobeoka } \\
\text { Hospital }\end{array}$ \\
\hline Shi $(2014)^{27}$ & $2006-2011$ & 84 & China & First Affiliated Hospital, China Medical University \\
\hline Xiao $(2014)^{28}$ & 2008-2011 & 33 & China & West China Hospital, Sichuan University Chengdu \\
\hline Yang $(2014)^{29}$ & $2008-2013$ & 86 & China & $\begin{array}{l}\text { Affiliated Hospital of Medical College, Qingdao } \\
\text { University }\end{array}$ \\
\hline Zhang $(2014)^{30}$ & $2002-2010$ & 88 & China & $\begin{array}{l}\text { Institute of Cardiothoracic Surgery, Changhai Hospital, } \\
\text { Second Military Medical University }\end{array}$ \\
\hline Dias $(2015)^{31}$ & 2009-2013 & 21 & Brazil & $\begin{array}{l}\text { Heart Institute of the University of São Paulo Medical } \\
\text { School }\end{array}$ \\
\hline Hiraoka $(2015)^{32}$ & $2005-2013$ & 26 & Japan & The Sakakibara Heart Institute of Okayama \\
\hline Katayama $(2015)^{33}$ & $1997-2011$ & 224 & Japan & $\begin{array}{l}\text { Hiroshima University Hospital; Hiroshima City Asa } \\
\text { General Hospital }\end{array}$ \\
\hline Ahmad $(2016)^{34}$ & 2013-2015 & 14 & Germany & $\begin{array}{l}\text { Johann-Wolfgang-Goethe University Frankfurt/Main, } \\
\text { Frankfurt am Main, Germany }\end{array}$ \\
\hline Gong $(2016)^{35}$ & 2014-2015 & 74 & China & $\begin{array}{l}\text { Beijing Anzhen Hospital Capital Medical University and } \\
\text { Beijing Institute of Heart Lung and Blood Vessel } \\
\text { Disease }\end{array}$ \\
\hline Leontyev $(2016)^{36}$ & $2005-2014$ & 509 & International & E-vita Open Registry \\
\hline $\operatorname{Ma}(2016)^{37}$ & $2010-2013$ & 99 & China & $\begin{array}{l}\text { Tongji Hospital, Tongji Medical College, Huazhong } \\
\text { University of Science and Technology }\end{array}$ \\
\hline Shrestha $(2016)^{38}$ & $2010-2014$ & 100 & Germany & Hannover Medical School \\
\hline Aalaei-Andabili $(2017)^{39}$ & $2010-2015$ & 48 & United States & University of Florida \\
\hline
\end{tabular}


TABLE 2. Continued

\begin{tabular}{|c|c|c|c|c|}
\hline First author (year) & Study period & $\mathbf{N}$ & Country & Institution \\
\hline Chen $(2017)^{40}$ & 2011-2015 & 20 & China & $\begin{array}{l}\text { Beijing Aortic Disease Center, Beijing Anzhen Hospital, } \\
\text { Capital Medical University }\end{array}$ \\
\hline $\mathrm{Hu}(2017)^{41}$ & $2008-2015$ & 106 & China & Renmin Hospital of Wuhan University \\
\hline Preventza $(2017)^{42}$ & $2010-2015$ & 37 & United States & $\begin{array}{l}\text { Baylor College of Medicine; Texas Heart Institute; } \\
\text { Michael E. DeBakey Veterans Affairs Medical Center; } \\
\text { Cleveland Clinic }\end{array}$ \\
\hline Verhoye $(2017)^{43}$ & 2009-2015 & 94 & France & French multicenter $\S$ \\
\hline Koizumi $(2017)^{44}$ & 2014-2016 & 30 & Japan & Kobe City Medical Center General Hospital \\
\hline Kreibich $(2018)^{45}$ & $2015-2017$ & 14 & Germany & University of Freiburg \\
\hline $\mathrm{Ma}(2018)^{46}$ & 2013-2015 & 132 & China & Huazhong University of Science and Technology \\
\hline Roselli $(2018)^{47}$ & $2009-2016$ & 72 & United States & Cleveland Clinic \\
\hline
\end{tabular}

$N$, Number of patients included in the study. *Upper entry, labeled Ma (2014), refers to data from acute cases; lower entry, labeled Ma (2014B), refers to data from chronic cases. $\dagger$ Institutions included Beijing Aortic Disease Center, Beijing Anzhen Hospital of Capital Medical University, Beijing Institute of Heart, Lung and Blood Vessel Diseases, and Beijing Engineering Research Center of Vascular Prostheses; Fu Wai Hospital and Cardiovascular Institute, Chinese Academy of Medical Sciences and State Key Laboratory of Cardiovascular Disease, National Center for Cardiovascular Disease; and Aortic Institute at Yale-New Haven. †̦Institutions included Leipzig Heart Center; West German Heart Centre Essen, University Hospital Essen; Sant'Orsola-Malpighi Hospital; Hospital Hietzing; Queen Elizabeth Hospital Birmingham; Robert Bosch Hospital; Tampere University Hospital Heart Center; Szpital Wojewódzki N2, OddziałKardiochirurgii; and Hospital Clinico, University of Barcelona. §Institutions included Pontchiallou University Hospital, Angers University Hospital, Reims University Hospital, and Louis Pradel University Hospital.

with coverage beyond $\mathrm{T} 8$ or stent length $15 \mathrm{~cm}$ or greater had a significantly higher incidence of SCI $(11.6 \%$ [95\% CI, $6.1-21.1]$ vs $2.5 \%$ [95\% CI, 1.5-4.0], $P<.001)$ (Figure E1).

TABLE 3. Summary of patient demographics*

\begin{tabular}{lccc}
\hline & $\begin{array}{c}\text { No. of } \\
\text { publications } \\
\text { reporting }\end{array}$ & Total N & $\begin{array}{c}\text { \% or mean } \\
\mathbf{( 9 5 \% ~ C I ) ~}\end{array}$ \\
\hline Total patients & 35 & 3154 & - \\
\hline Age (y) & 29 & 2785 & $55.3(51.3-59.3)$ \\
\hline Male & 33 & 2274 & $73.6(70.6-76.4)$ \\
\hline Urgent/emergency & 33 & 1705 & $53.2(40.4-65.7)$ \\
\hline Smoking & 6 & 158 & $56.3(46.2-66.0)$ \\
\hline Diabetes & 20 & 248 & $10.8(7.6-15.2)$ \\
\hline Hypertension & 26 & 2039 & $75.9(71.3-79.9)$ \\
\hline Renal insufficiency & 24 & 220 & $9.0(6.2-13.0)$ \\
\hline CAD & 19 & 251 & $12.0(7.9-17.9)$ \\
\hline COPD & 17 & 273 & $18.4(13.3-24.8)$ \\
\hline Previous sternotomies & 8 & 75 & $18.5(9.7-32.4)$ \\
\hline Previous aortic/cardiac & 12 & 322 & $31.5(19.8-46.0)$ \\
\hline complications & & & \\
\hline Prior stroke & 19 & 158 & $7.2(4.7-10.8)$ \\
\hline CPB time (min) & 29 & 2619 & $203.6(191.7-215.5)$ \\
\hline Follow-up (mo) & 15 & 742 & $30.4(24.3-36.4)$ \\
\hline Hospital stay (d) & 9 & 459 & $15.2(14.5-15.8)$ \\
\hline C & & & \\
\hline
\end{tabular}

$C I$, Confidence interval; $C A D$, coronary artery disease; $C O P D$, chronic obstructive pulmonary disease; $C P B$, cardiopulmonary bypass. *Numbers are pooled data calculated in meta-analysis software that accounts for the differing weights of the studies.

\section{Acute Type A versus Nonacute Type A and Aneurysm}

When we compared studies performed only in patients with acute type A aortic dissection $(\mathrm{n}=12,1300$ patients) $)^{21,23,25,27-30,35,37,41,46,47}$ with studies performed only in patients with nonacute type A dissection and aneurysm $\left(\mathrm{n}=14,741\right.$ patients) ${ }^{14,15,17,19,22,24-26,34,40,42-45}$ we found the following results: The pooled mortality rate was $9.2 \%$ (95\% CI, 6.9-12.4) in the patients with acute type A and $7.6 \%(95 \% \mathrm{CI}, 4.9-11.4)$ in the patients with nonacute dissection and aneurysm $(P=.46)$. The pooled rate of stroke in these 2 groups was $9.3 \%$ (95\% CI, 4.5-18.5) and $6.6 \%(95 \% \mathrm{CI}, 3.1-13.5)(P=.51)$, and the pooled rate of SCI was $2.4 \%(95 \% \mathrm{CI}, 1.3-4.2)$ and $5.2 \%(95 \%$ CI, 3.1-8.5) $(P=.05)$, respectively (Figure E2).

The incidence of the overall composite adverse outcome (mortality, stroke, and SCI) was $22.0 \%$ (95\% CI, 13.633.6) for the acute type A aortic dissection group and $16.5 \%$ (95\% CI 9.6-26.7) for the nonacute dissection and aneurysm groups $(P=.41)$.

\section{DISCUSSION}

Since the original description of extensive aortic replacement using the ET technique by Borst and colleagues ${ }^{48}$ techniques and technology have continued to develop in an effort to simplify complex aortic repairs. The evidence is ambiguous regarding the value of FET repair for extensive aortic pathologies. Kato and colleagues ${ }^{49}$ introduced the placement of an endovascular prosthesis in the descending thoracic aorta; since then, few single-device hybrid endoprostheses have been used in Europe and Asia. Additionally, custom-made 
TABLE 4. Summary of clinical outcomes

\begin{tabular}{|c|c|c|c|c|}
\hline First author (year) & $\mathbf{N}$ & $\frac{\text { Overall stroke }}{\%(95 \% \text { CI })}$ & $\begin{array}{c}\text { Overall SCI/paralysis/ } \\
\text { paraplegia }\end{array}$ & $\frac{\text { Operative mortality }}{\%(95 \% \text { CI })}$ \\
\hline Usui $(2002)^{14}$ & 24 & $4.2(0.0-12.2)$ & $12.5(0.0-25.7)$ & $0.0(0.0-0.0)$ \\
\hline Flores $(2006)^{15}$ & 25 & $16.0(1.6-30.4)$ & $24.0(7.3-40.7)$ & $12.0(0.0-24.7)$ \\
\hline Shimamura $(2008)^{16}$ & 126 & $5.6(1.6-9.6)$ & $6.3(2.1-10.6)$ & $5.6(1.6-9.6)$ \\
\hline $\operatorname{Li}(2009)^{17}$ & 31 & $3.2(0.0-9.4)$ & $0.0(0.0-0.0)$ & $6.5(0.0-15.1)$ \\
\hline Chen $(2010)^{18}$ & 28 & $10.7(0.0-22.2)$ & $0.0(0.0-0.0)$ & $14.3(1.3-27.2)$ \\
\hline Sun $(2010)^{19}$ & 19 & $5.3(0.0-15.3)$ & $0.0(0.0-0.0)$ & $5.3(0.0-15.3)$ \\
\hline Lima $(2012)^{20}$ & 31 & $12.9(1.1-24.7)$ & $12.9(1.1-24.7)$ & $9.7(0.0-20.1)$ \\
\hline Shen $(2012)^{21}$ & 38 & $0.0(0.0-0.0)$ & $5.3(0.0-12.4)$ & $7.9(0.0-16.5)$ \\
\hline Zhao $(2012)^{22}$ & 24 & $4.2(0.0-12.2)$ & $0.0(0.0-0.0)$ & $4.2(0.0-12.2)$ \\
\hline Hoffman $(2013)^{23}$ & 32 & $0.0(0.0-0.0)$ & $0.0(0.0-0.0)$ & $3.1(0.0-9.2)$ \\
\hline Di Marco $(2014)^{24}$ & 11 & $9.1(0.0-26.1)$ & $0.0(0.0-0.0)$ & $0.0(0.0-0.0)$ \\
\hline $\mathrm{Ma}(2014)^{25 *}$ & 456 & $2.9(1.3-4.4)$ & $2.4(1.0-3.8)$ & $8.1(5.6-10.6)$ \\
\hline $\mathrm{Ma}(2014 \mathrm{~B})^{25 *}$ & 347 & $0.9(0.0-1.8)$ & $2.3(0.7-3.9)$ & $4.3(2.2-6.5)$ \\
\hline Nakamura $(2014)^{26}$ & 51 & NR & $3.9(0.0-9.2)$ & NR \\
\hline Shi $(2014)^{27}$ & 84 & $33.3(23.3-43.4)$ & $0.0(0.0-0.0)$ & $6.0(0.9-11.0)$ \\
\hline Xiao $(2014)^{28}$ & 33 & $0.0(0.0-0.0)$ & $0.0(0.0-0.0)$ & $18.2(5.0-31.3)$ \\
\hline Yang $(2014)^{29}$ & 86 & NR & $2.3(0.0-5.5)$ & $5.8(0.9-10.8)$ \\
\hline Zhang $(2014)^{30}$ & 88 & $14.8(7.4-22.2)$ & $0.0(0.0-0.0)$ & $5.7(0.8-10.5)$ \\
\hline Dias $(2015)^{31}$ & 21 & $4.8(0.0-13.9)$ & $9.5(0.0-22.1)$ & $14.3(0.0-29.3)$ \\
\hline Hiraoka $(2015)^{32}$ & 26 & $7.7(0.0-17.9)$ & $11.5(0.0-23.8)$ & $0.0(0.0-0.0)$ \\
\hline Katayama $(2015)^{33}$ & 224 & $2.7(0.6-4.8)$ & $3.6(1.1-6.0)$ & $3.6(1.1-6.0)$ \\
\hline Ahmad $(2016)^{34}$ & 14 & $14.3(0.0-32.6)$ & $0.0(0.0-0.0)$ & $0.0(0.0-0.0)$ \\
\hline Gong $(2016)^{35}$ & 74 & $6.8(1.0-12.5)$ & $6.8(1.0-12.5)$ & $12.2(4.7-19.6)$ \\
\hline Leontyev $(2016)^{36}$ & 509 & $8.1(5.7-10.4)$ & $7.5(5.2-9.7)$ & $15.9(12.7-19.1)$ \\
\hline Ma $(2016)^{37}$ & 99 & $34.3(25.0-43.7)$ & $0.0(0.0-0.0)$ & $17.2(9.7-24.6)$ \\
\hline Shrestha $(2016)^{38}$ & 100 & $9.0(3.4-14.6)$ & $7.0(2.0-12.0)$ & $7.0(2.0-12.0)$ \\
\hline Aalaei-Andabili $(2017)^{39}$ & 48 & $6.3(0.0-13.1)$ & $4.2(0.0-9.8)$ & $16.7(6.1-27.2)$ \\
\hline Chen $(2017)^{40}$ & 20 & NR & $5.0(0.0-14.6)$ & $5.0(0.0-14.6)$ \\
\hline $\mathrm{Hu}(2017)^{41}$ & 106 & $4.7(0.7-8.8)$ & $0.0(0.0-0.0)$ & $7.5(2.5-12.6)$ \\
\hline Preventza $(2017)^{42}$ & 37 & $5.4(0.0-12.7)$ & $5.4(0.0-12.7)$ & $21.6(8.4-34.9)$ \\
\hline Verhoye $(2017)^{43}$ & 94 & $9.6(3.6-15.5)$ & $4.3(0.2-8.3)$ & $11.7(5.2-18.2)$ \\
\hline Koizumi $(2017)^{44}$ & 30 & $10.0(0.0-20.7)$ & $3.3(0.0-9.8)$ & $0.0(0.0-0.0)$ \\
\hline Kreibich $(2018)^{45}$ & 14 & $14.3(0.0-32.6)$ & $0.0(0.0-0.0)$ & $0.0(0.0-0.0)$ \\
\hline $\operatorname{Ma}(2018)^{46}$ & 132 & $40.9(32.5-49.3)$ & $0.0(0.0-0.0)$ & $14.4(8.4-20.4)$ \\
\hline Roselli $(2018)^{47}$ & 72 & $2.8(0.0-6.6)$ & $4.2(0.0-8.8)$ & $4.2(0.0-8.8)$ \\
\hline All studies (range) & 3154 & $0-40.9$ & $0-24.0$ & $0-21.6$ \\
\hline
\end{tabular}

$N$, Number of patients included in study; $S C I$, spinal cord ischemia; $C I$, confidence interval; $N R$, not reported. *Upper entry, labeled Ma (2014), refers to data from acute cases; lower entry, labeled Ma (2014B), refers to data from chronic cases.

devices have become popular. The expected benefits of FET are 2-fold: It allows debranching of the arch vessels and arch replacement by an open technique and creates an optimal proximal landing zone for thoracic endovascular repair of the remaining descending thoracic aorta, which can be achieved in the same operative session or in a second stage by retrograde stent delivery. A virtual seal in the descending thoracic aorta also can be achieved. Second-stage repair of the entire thoracoabdominal aorta also can be accomplished by open repair, 
TABLE 5. Pooled outcome rates $(95 \%$ confidence intervals), with corresponding results of heterogeneity and publication bias

\begin{tabular}{|c|c|c|c|c|}
\hline Outcome & No. of studies & Pooled rate, \% $(95 \%$ CI $)$ & $\begin{array}{c}\text { Heterogeneity } \mathbf{I}^{2} \%(95 \% \\
\text { CI) prediction interval }\end{array}$ & $\begin{array}{c}\text { Publication bias Egger } \\
\text { test } P \text { (1-tailed) }\end{array}$ \\
\hline Overall stroke & 32 & $7.6(5.0-11.5)$ & $\begin{array}{c}88.3(84.5-91.1) \\
2.9-12.3\end{array}$ & .003 \\
\hline Overall SCI & 35 & $4.7(3.5-6.2)$ & $\begin{array}{l}46.3(20.1-63.9) \\
2.8-6.6\end{array}$ & .008 \\
\hline Operative mortality & 34 & $8.8(7.0-10.9)$ & $\begin{array}{c}60.5(42.5-72.8) \\
6.4-11.2\end{array}$ & .002 \\
\hline
\end{tabular}

CI, Confidence interval; SCI, spinal cord ischemia.

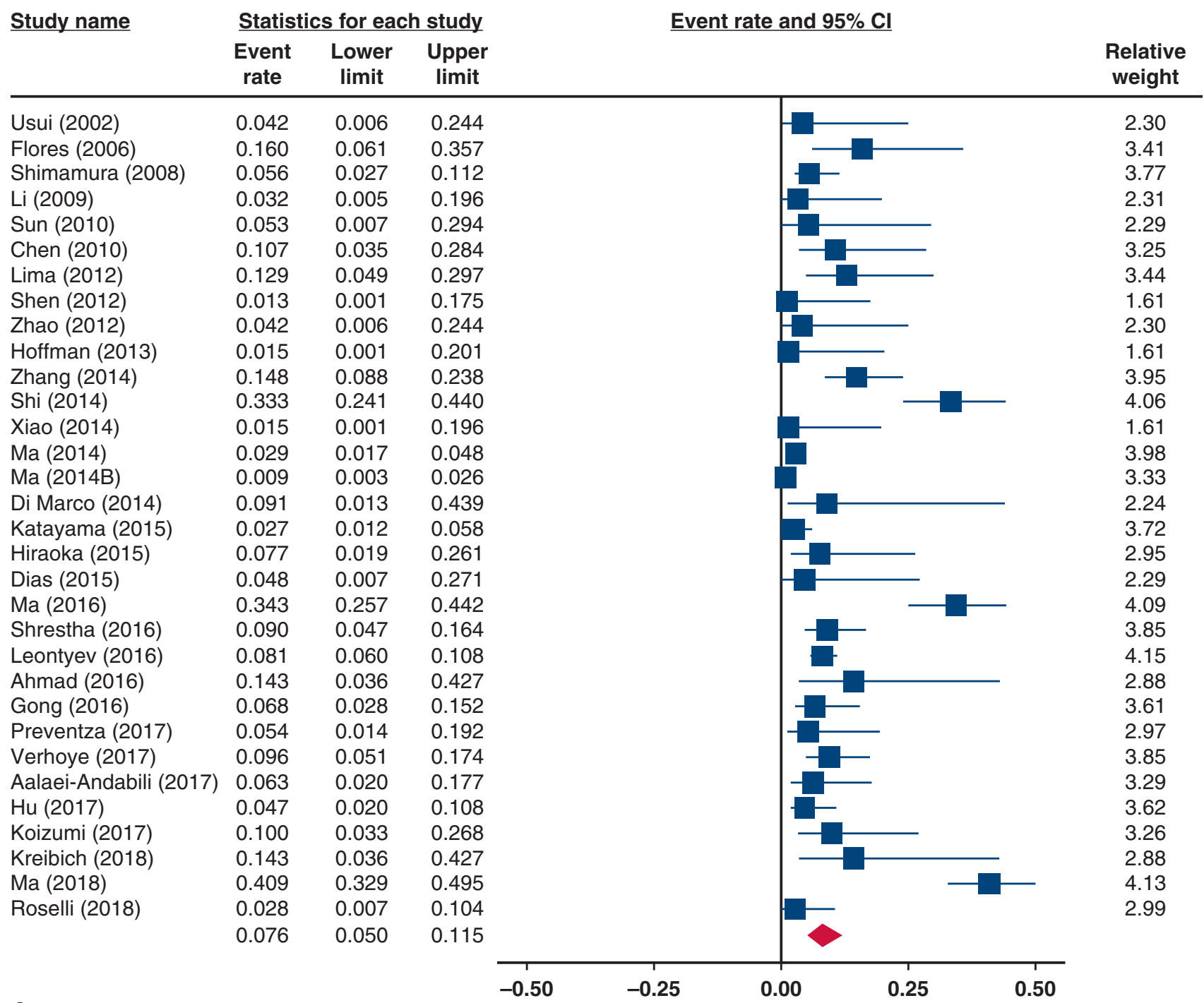

A

FIGURE 2. Event rates for adverse outcomes. Forest plots show the event rates for (A) overall, persistent, or transient stroke (7.6\%; 95\% CI, 5.0-11.5); (B) spinal cord injury, including persistent and transient paralysis, paraplegia, and paraparesis ( $4.7 \%$; $95 \%$ CI, 3.5-6.2); and (C) overall, operative, 30-day, or inhospital mortality $(8.8 \% ; 95 \%$ CI, 7.0-10.9). The estimate of the event rate of each study corresponds to the middle of the blue squares, and the horizontal line through the squares shows the $95 \%$ CI. The summary pooled event rate is represented by the middle of the solid red diamond, with the width of the diamond representing the $95 \%$ CI. CI, Confidence interval. 


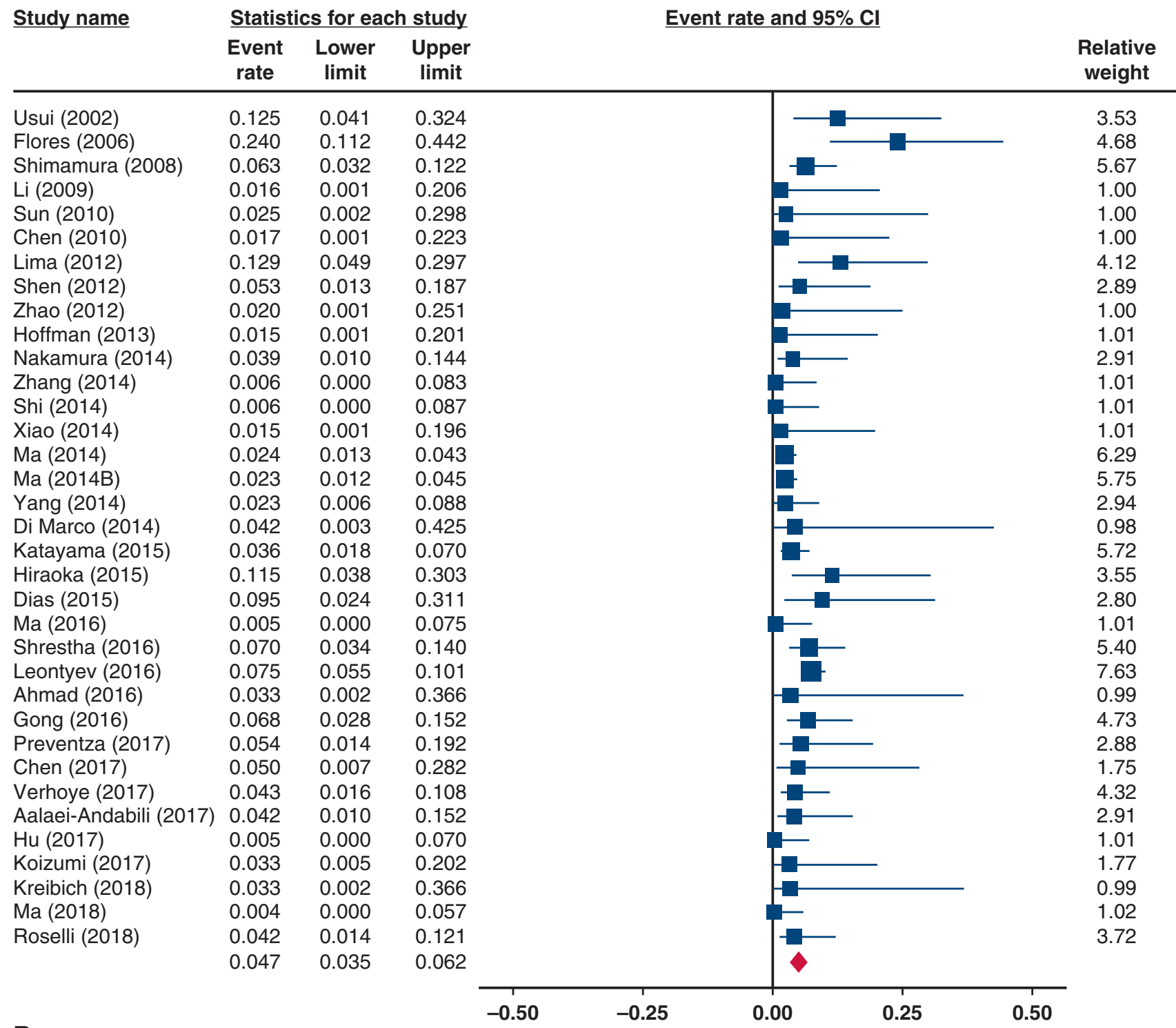

B

FIGURE 2. Continued

total endovascular repair with custom-made branched endografts, or hybrid repair.

In the present meta-analysis, we reviewed the reported data for 3145 patients from 35 studies, with a focus on mortality and neurologic events associated with this procedure (Figure 4 ). The $8.8 \%$ pooled rate of overall mortality is similar to rates produced by other metaanalyses, ${ }^{50,51}$ although our analysis included only total arch FET procedures, whereas the others ${ }^{50,51}$ included both total arch operations with FET and proximal arch procedures with stenting of the descending thoracic aorta.

This mortality rate, which reflects all emergency $(53.2 \%)$ and elective cases, is less than the $14.5 \%$ rate reported for conventional ET procedures in a recent systematic review. ${ }^{50}$ One possible explanation is that FET procedures are more likely than conventional ET procedures to be performed in specialized aortic surgery centers with access to specific devices.

We found that the pooled estimate for overall permanent or transient stroke reported in 32 studies was $7.6 \%$, which is similar to what is reported for the conventional ET repair (Figure 4). ${ }^{50}$ However, it is higher than what was reported in the previous FET meta-analyses. ${ }^{50,51}$ This difference can be explained by our including only studies of total arch procedures, which are more complex and lengthy - and thus may incur a higher risk of strokethan proximal arch or hemiarch procedures. The mode of 


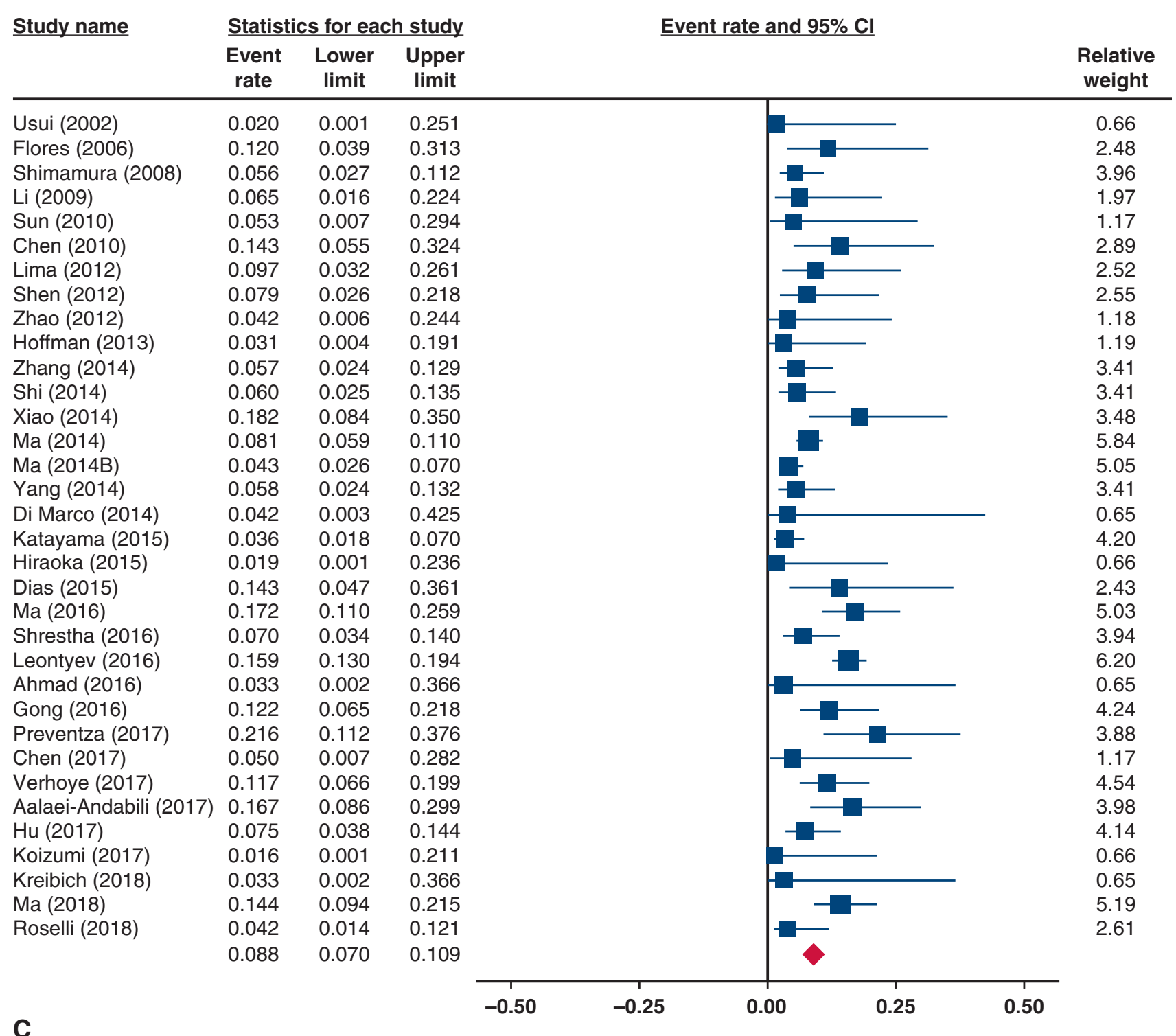

FIGURE 2. Continued

cerebral perfusion used in the included studies was variously antegrade cerebral perfusion, retrograde cerebral perfusion, and a combination of both, with the most common being antegrade cerebral perfusion. Various levels of hypothermia were used in the studies. Unfortunately, because the studies varied in the ways in which temperatures were measured (rectal or nasopharyngeal) and reported (mean with standard deviation, mean with range, range only), we were not able to examine the relation between hypothermic temperature and overall stroke risk.

Of the 35 FET studies, 12 included only acute type A aortic dissection cases. The overall composite adverse event rate was slightly higher in the acute type A aortic dissection cases than in the nonacute and aneurysm cases, as were the rates of operative mortality and stroke (Figure 4). This may reflect the urgency of performing a type A dissection procedure and the complexity of the total arch procedure in these patients, whose preoperative characteristics may include preoperative malperfusion, instability, and occasional poor preoperative neurologic status, which have specific implications for acute type A dissection cases and can drive a dismal outcome. We did notice less SCI overall with the acute dissection cases than with the nonacute dissection and aneurysm cases, maybe because these patients' higher rates of mortality and stroke resulted in fewer of them being evaluated for spinal cord deficit. In addition, the status of patency of the false lumen and its effect on the risk of spinal cord deficit are unknown. 


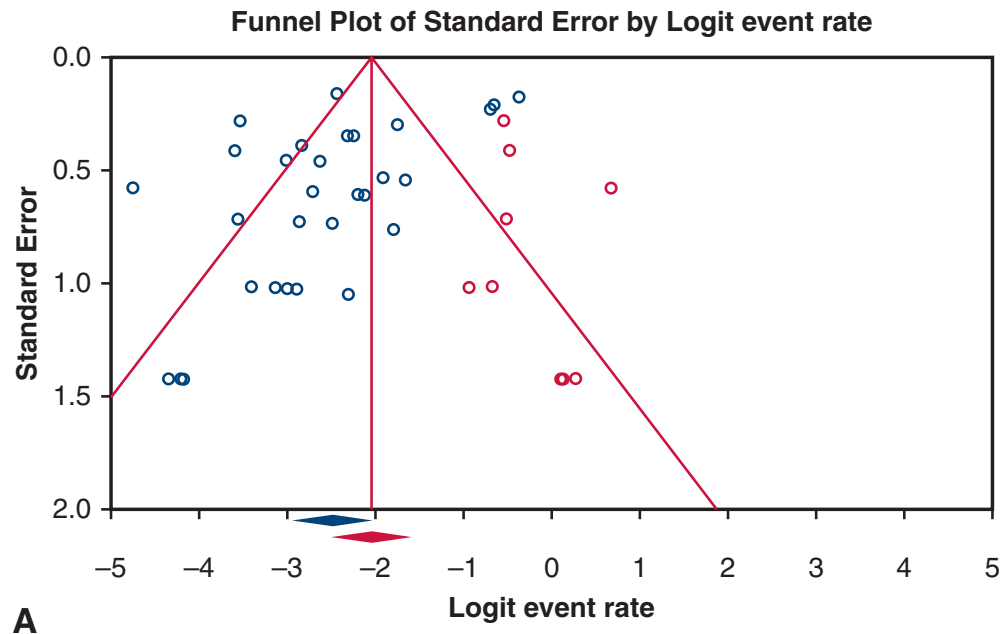

A

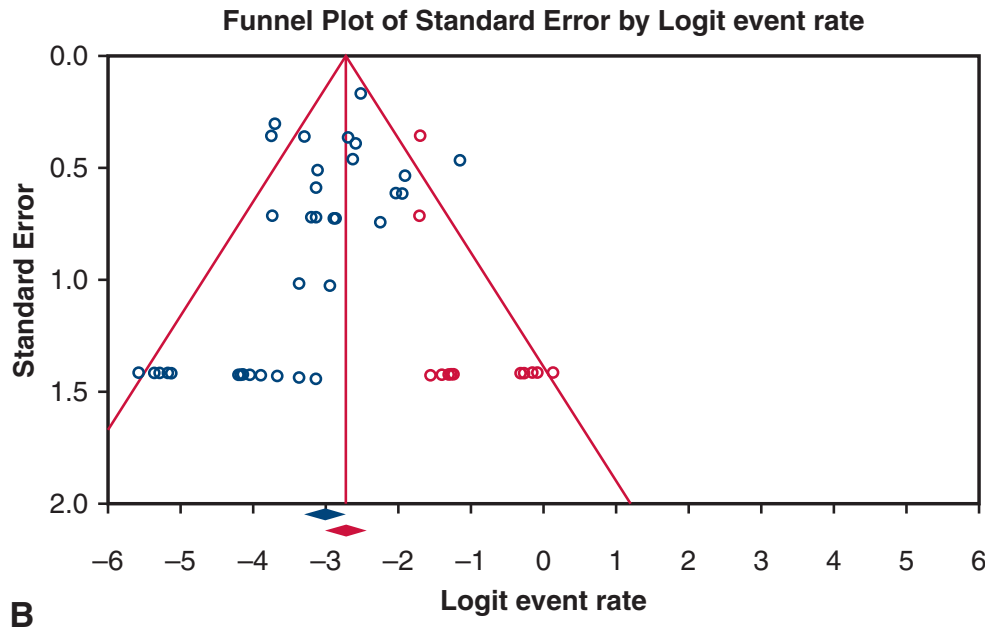

Funnel Plot of Standard Error by Logit event rate

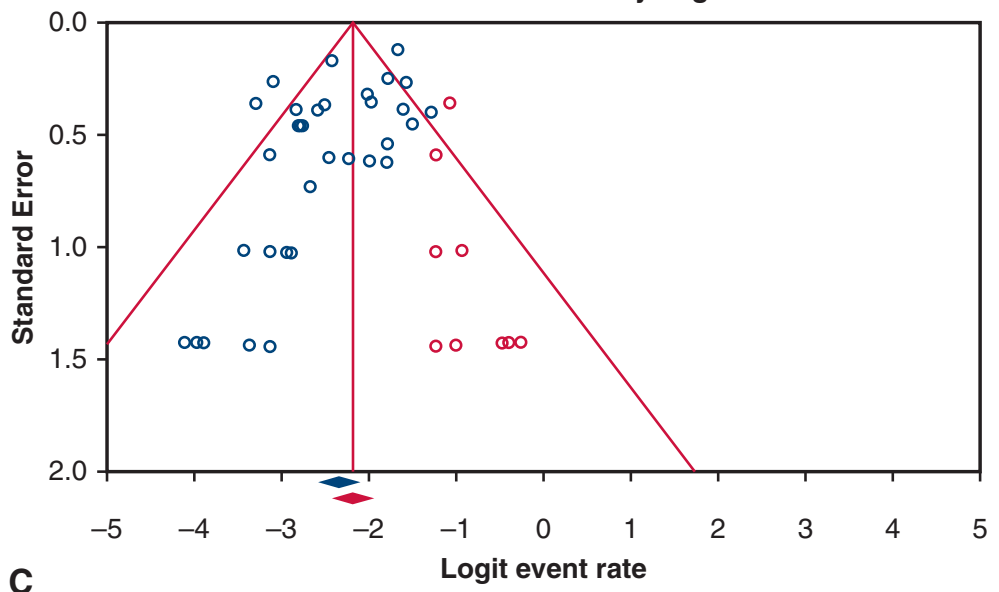

FIGURE 3. Logit event rates for adverse outcomes. Funnel plots show these rates for (A) stroke (11.0\%; 95\% CI, 7.9-16.0), (B) spinal cord injury (6.1\%; $95 \% \mathrm{CI}, 4.6-8.1)$, and (C) mortality (10.1\%; 95\% CI, 8.2-12.4). Blue circles represent the studies used in the analysis, and red circles represent the studies that were imputed with the trim-and-fill method. Note: "Ma (2014)" refers to data from acute cases; "Ma (2014B)" refers to data from chronic cases in the same study. 


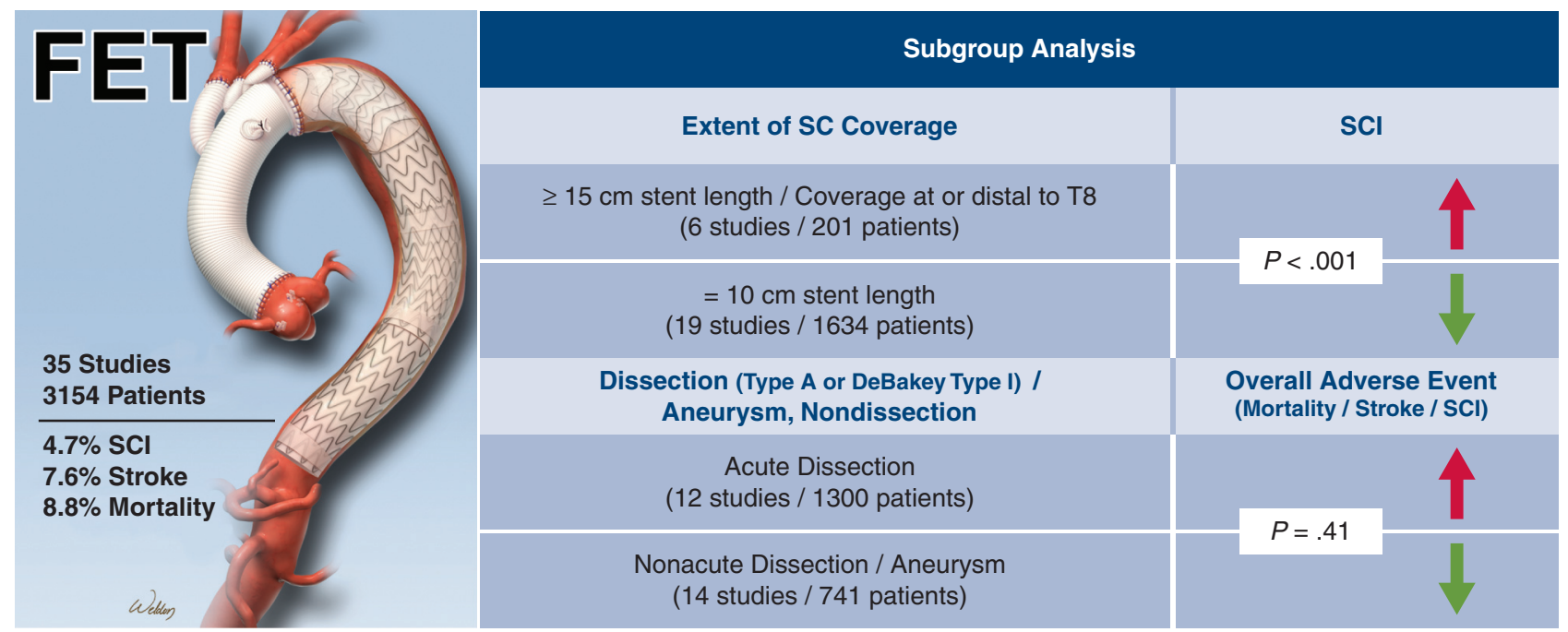

FIGURE 4. A visual summary of the main points of our study. The overall pooled rates of the outcomes of interest were $4.7 \%$ for overall SCI, $7.6 \%$ for overall stroke, and $8.8 \%$ for operative mortality. Additionally, 2 subgroup analyses were performed: One showed that SCI was significantly more frequent in the patients with longer stents or coverage at or beyond T8. The other subgroup analysis found that the FET technique was associated with higher rates of mortality and stroke in patients with acute type A dissection, and the overall adverse event rate (which included mortality, stroke, and SCI) was higher in these patients, too. FET, Frozen elephant trunk; SC, spinal cord; SCI, spinal cord ischemia.

Paralysis and paraparesis are potentially deadly adverse consequences of thoracic endovascular repair, and they remain a major concern with the FET procedure. Data regarding spinal cord protection from thoracic endovascular aortic repair and open thoracoabdominal procedures $^{52}$ can be used to guide FET procedures. As more data have become available regarding the potential for spinal cord compromise, lessons have been learned and registries have been created ${ }^{36,43,53}$ to capture procedures and outcomes and to examine the association between extensive spinal cord coverage and paralysis or paraparesis.

In the International E-vita Open Registry, ${ }^{53}$ among 90 patients who underwent procedures for chronic dissection (which was type A in $77 \%$ of the cases) of the thoracic aorta, $8(8.9 \%)$ developed SCI. Although no correlation between extensive coverage with the FET and SCI was seen in that study, the rate of SCI was higher in patients whose distal landing zone was at or below T10, and no patient with SCI had stent coverage to less than T8. In our meta-analysis, we saw significantly higher rates of paralysis or paraparesis in patients with coverage at $\mathrm{T} 8$ or beyond or a stent length of $15 \mathrm{~cm}$ or longer $(11.6 \%$ vs $2.5 \%, P<.001)$ compared with a length of $10 \mathrm{~cm}$ (Figure 4). We acknowledge that the exact location of the suture line proximal or distal to the left subclavian artery, which could affect thoracic spine coverage, was not consistently clear in the articles included in our analysis. Use of cerebrospinal fluid drainage was reported in only 4 studies, ${ }^{27,33,36,43}$ so we could not determine whether this adjunct was protective. In addition, the relationship between circulatory arrest temperature and spinal cord injury was not evaluated for the reasons stated earlier. In a general sense, it is worth noting that many of the survivors of FET will later go on to have an open thoracoabdominal repair, and such interventions have had good results. ${ }^{54}$

\section{Study Limitations}

This meta-analysis study had several limitations. The studies analyzed were observational, with the inherent bias and lack of uniformity in surgical methodology and reporting. Summarizing observational studies presents challenges, including the risk of bias inherent in these designs in a widely heterogeneous literature. We do not have patient-level data, so we are unable to relate risk factors to the outcomes of interest with any certainty. Spinal cord drainage was not reported in the majority of studies. Specific definitions of chronic and acute dissection were also not reported. Most of the studies did not examine permanent and transient events separately, and no information on race or ethnicity was included. The characterization of acute and chronic dissection was based on the criteria used in each study, with no specification as to timing. A variety of devices were used in these studies, from commercially available single-piece endoprostheses to custom-made FET prostheses. In addition, this study did not examine the outcomes of the FET procedure as a single-stage operation versus the first of 2 stages, with intended completion and reintervention at the second stage. Survival beyond the operative period also was not examined because it was reported in only 4 studies.

Nevertheless, this meta-analysis is of vital importance because FET is becoming more popular in the surgical 
community. In contrast to the other reviews, ${ }^{51,52}$ our analysis included only total arch repairs, emphasizing that for reporting purposes, proximal arch or hemiarch repair in combination with stent-graft placement in the descending thoracic aorta should not be viewed or reported as an FET procedure because the results could be different.

\section{CONCLUSIONS}

Reports of the effectiveness of any new procedure or device must be interpreted cautiously because results from the specialized centers where these innovations typically are first used may not reflect how the device will perform elsewhere. This meta-analysis is an effort to evaluate mortality and neurologic events associated with this relatively new but increasingly popular procedure. In cases of acute type A aortic dissection, this technique should be performed with caution. In addition, landing zone at $\mathrm{T} 8$ or beyond or a stent graft length of $15 \mathrm{~cm}$ or more was a significant predictor of SCI. This is of utmost importance, because industry is developing single-graft endoprostheses to treat extensive aortic pathology.

\section{Webcast}

You can watch a Webcast of this AATS meeting presentation by going to: https://aats.blob.core.windows.net/ media/19\%20AM/Sunday_May5/206F/206F/S43\%20-\% 20Rapid \%20Fire \%20Abstracts\%20III/S43_3_webcast_ 075549987.mp4.

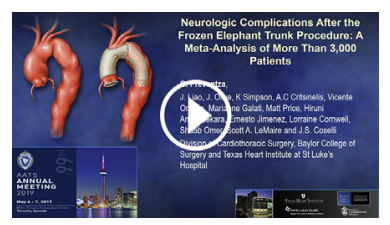

\section{Conflict of Interest Statement}

Dr Coselli consults for, receives royalties and a departmental educational grant from, and participates in clinical trials for Terumo Aortic; consults and participates in clinical trials for Medtronic, and WL Gore \& Associates; and serves as a co-investigator for CytoSorbents. Dr Coselli's work is partly funded by the Cullen Foundation. Dr Preventza consults for, participates in clinical trials for, and has received travel funds from Medtronic, Inc; serves as a consultant for Terumo Aortic and WL Gore \& Associates; and has received travel funds from Cook Medical. Dr LeMaire has served as a consultant for Terumo Aortic and Baxter Healthcare; has served as an Advisory Panel Member for Biom'up and Acer Therapeutics; has served as a principal investigator for clinical studies sponsored by Terumo Aortic and CytoSorbents; and has served as a coinvestigator for clinical studies sponsored by WL Gore \&
Associates. Dr LeMaire's work is supported in part by the Jimmy and Roberta Howell Professorship in Cardiovascular Surgery at Baylor College of Medicine. All other authors have nothing to disclose with regard to commercial support.

Hiruni Amarasekara, MS, and Susan Y. Green, MPH, helped evaluate articles and reviewed the final article. Scott Weldon, MA, CMI, FAMI, contributed to the artwork and design of the visual abstract. Stephen N. Palmer, PhD, ELS, contributed to the editing of the article.

\section{References}

1. Castrovinci S, Murana G, de Maat GE, Smith T, Schepens MA, Heijmen RH, et al. The classic elephant trunk technique for staged thoracic and thoracoabdominal aortic repair: long-term results. J Thorac Cardiovasc Surg. 2015;149: 416-22.

2. Crawford ES, Coselli JS, Svensson LG, Safi HJ, Hess KR. Diffuse aneurysmal disease (chronic aortic dissection, Marfan, and mega aorta syndromes) and multiple aneurysm. Treatment by subtotal and total aortic replacement emphasizing the elephant trunk operation. Ann Surg. 1990;211:521-37.

3. Etz CD, Plestis KA, Kari FA, Luehr M, Bodian CA, Spielvogel D, et al. Staged repair of thoracic and thoracoabdominal aortic aneurysms using the elephant trunk technique: a consecutive series of 215 first stage and 120 complete repairs. Eur J Cardiothorac Surg. 2008;34:605-15.

4. Ius F, Hagl C, Haverich A, Pichlmaier M. Elephant trunk procedure 27 years after Borst: what remains and what is new? Eur J Cardiothorac Surg. 2011; 40:1-11.

5. Safi HJ, Miller CC 3rd, Estrera AL, Huynh TT, Rubenstein FS, Subramaniam MH, et al. Staged repair of extensive aortic aneurysms: morbidity and mortality in the elephant trunk technique. Circulation. 2001;104:2938-42.

6. Svensson LG, Rushing GD, Valenzuela ES, Rafael AE, Batizy LH, Blackstone EH, et al. Modifications, classification, and outcomes of elephanttrunk procedures. Ann Thorac Surg. 2013;96:548-58.

7. Preventza O, Al-Najjar R, LeMaire SA, Weldon S, Coselli JS. Total arch replacement with frozen elephant trunk technique. Ann Cardiothorac Surg. 2013;2: 649-52.

8. Shrestha M, Bachet J, Bavaria J, Carrel TP, De Paulis R, Di Bartolomeo R, et al. Current status and recommendations for use of the frozen elephant trunk technique: a position paper by the Vascular Domain of EACTS. Eur J Cardiothorac Surg. 2015;47:759-69.

9. Armour BS, Courtney-Long EA, Fox MH, Fredine H, Cahill A. Prevalence and causes of paralysis-United States, 2013. Am J Public Health. 2016;106:1855-7.

10. Moher D, Shamseer L, Clarke M, Ghersi D, Liberati A, Petticrew M, et al. Preferred reporting items for systematic review and meta-analysis protocols (PRISMA-P) 2015 statement. Syst Rev. 2015;4:1.

11. DerSimonian R, Laird N. Meta-analysis in clinical trials. Control Clin Trials. 1986; 7:177-88.

12. Higgins JP, Thompson SG, Deeks JJ, Altman DG. Measuring inconsistency in meta-analyses. BMJ. 2003;327:557-60.

13. Borenstein M, Higgins JP, Hedges LV, Rothstein HR. Basics of metaanalysis: $\mathrm{I}^{2}$ is not an absolute measure of heterogeneity. Res Synth Methods. 2017;8:5-18.

14. Usui A, Fujimoto K, Ishiguchi T, Yoshikawa M, Akita T, Ueda Y. Cerebrospinal dysfunction after endovascular stent-grafting via a median sternotomy: the frozen elephant trunk procedure. Ann Thorac Surg. 2002;74:S1821-4; discussion S1825-S1832.

15. Flores J, Kunihara T, Shiiya N, Yoshimoto K, Matsuzaki K, Yasuda K. Extensive deployment of the stented elephant trunk is associated with an increased risk of spinal cord injury. J Thorac Cardiovasc Surg. 2006;131:336-42.

16. Shimamura K, Kuratani T, Matsumiya G, Kato M, Shirakawa Y, Takano H, et al. Long-term results of the open stent-grafting technique for extended aortic arch disease. J Thorac Cardiovasc Surg. 2008;135:1261-9.

17. Li B, Sun L, Chang Q, Zhu J, Yu C, Liu Y, et al. Total arch replacement with stented elephant trunk technique: a proposed treatment for complicated Stanford type B aortic dissection. J Card Surg. 2009;24:704-9.

18. Chen X, Huang F, Xu M, Wang L, Jiang Y, Xiao L, et al. The stented elephant trunk procedure combined total arch replacement for DeBakey I aortic 
dissection: operative result and follow-up. Interact Cardiovasc Thorac Surg. 2010;11:594-8.

19. Sun L, Zhao X, Chang Q, Zhu J, Liu Y, Yu C, et al. Repair of chronic type B dissection with aortic arch involvement using a stented elephant trunk procedure. Ann Thorac Surg. 2010;90:95-100.

20. Lima B, Roselli EE, Soltesz EG, Johnston DR, Pujara AC, Idrees J, et al. Modified and "reverse" frozen elephant trunk repairs for extensive disease and complications after stent grafting. Ann Thorac Surg. 2012;93:103-9.

21. Shen K, Tang H, Jing R, Liu F, Zhou X. Application of triple-branched stent graft for Stanford type A aortic dissection: potential risks. Eur J Cardiothorac Surg. 2012;41:e12-7.

22. Zhao HP, Zhu JM, Ma WG, Zheng J, Liu YM, Sun LZ. Total arch replacement with stented elephant trunk technique for acute type B aortic dissection involving the aortic arch. Ann Thorac Surg. 2012;93:1517-22.

23. Hoffman A, Damberg ALM, Schalte G, Mahnken AH, Raweh A, Autschbach R. Thoracic stent graft sizing for frozen elephant trunk repair in acute type A dissection. J Thorac Cardiovasc Surg. 2013;145:964-9.e1.

24. Di Marco L, Pacini D, Leone A, Pantaleo A, Cefarelli M, Di Eusanio M. The Thoraflex hybrid frozen elephant trunk device: the Bologna experience. $J$ Vasc Endovasc Surg. 2014;21:117-23.

25. Ma WG, Zheng J, Zhang W, Sun K, Ziganshin BA, Wang LF, et al. Frozen elephant trunk with total arch replacement for type A aortic dissections: does acuity affect operative mortality? J Thorac Cardiovasc Surg. 2014;148:963-72.

26. Nakamura K, Nagahama H, Nakamura E, Yano M, Matsuyama M, Nishimura M, et al. Predictors of early and late outcome after total arch replacement for atherosclerotic aortic arch aneurysm. Gen Thorac Cardiovasc Surg. 2014;62:31-7.

27. Shi E, Gu T, Yu Y, Yu L, Wang C, Fang Q, et al. Early and midterm outcomes of hemiarch replacement combined with stented elephant trunk in the management of acute DeBakey type I aortic dissection: comparison with total arch replacement. J Thorac Cardiovasc Surg. 2014;148:2125-31.

28. Xiao Z, Meng W, Zhu D, Guo Y, Zhang E. Treatment strategies for left subclavian artery during total arch replacement combined with stented elephant trunk implantation. J Thorac Cardiovasc Surg. 2014;147:639-43.

29. Yang SM, Xu P, Li CX, Huang Q, Gao HB, Li ZF, et al. A modified total arch replacement combined with a stented elephant trunk implantation for acute type A dissection under deep hypothermic circulatory arrest and selective antegrade cerebral perfusion. J Cardiothorac Surg. 2014;9:140.

30. Zhang H, Lang X, Lu F, Song Z, Wang J, Han L, et al. Acute type A dissection without intimal tear in arch: proximal or extensive repair? J Thorac Cardiovasc Surg. 2014; $147: 1251-5$

31. Dias RR, Duncan JA, Vianna DS, de Faria LB, Fernandes F, Ramirez FJ, et al. Surgical treatment of complex aneurysms and thoracic aortic dissections with the Frozen Elephant Trunk technique. Rev Bras Cir Cardiovasc. 2015:30:205-10.

32. Hiraoka A, Chikazawa G, Tamura K, Totsugawa T, Sakaguchi T, Yoshitaka H. Clinical outcomes of different approaches to aortic arch disease. J Vasc Surg. 2015;61:88-95.

33. Katayama K, Uchida N, Katayama A, Takahashi S, Takasaki T, Kurosaki T, et al. Multiple factors predict the risk of spinal cord injury after the frozen elephant trunk technique for extended thoracic aortic disease. Eur J Cardiothorac Surg. 2015;47:616-20.

34. El-Sayed Ahmad A, Risteski P, Papadopoulos N, Radwan M, Moritz A, Zierer A. Minimally invasive approach for aortic arch surgery employing the frozen elephant trunk technique. Eur J Cardiothorac Surg. 2016;50:140-4.

35. Gong M, Ma WG, Guan XL, Wang LF, Li JC, Lan F, et al. Moderate hypothermic circulatory arrest in total arch repair for acute type A aortic dissection: clinical safety and efficacy. J Thorac Dis. 2016;8:925-33.

36. Leontyev S, Tsagakis K, Pacini D, Di Bartolomeo R, Mohr FW, Weiss G, et al. Impact of clinical factors and surgical techniques on early outcome of patients treated with frozen elephant trunk technique by using EVITA open stent-graft: results of a multicentre study. Eur J Cardiothorac Surg. 2016;49:660-6.

37. Ma M, Liu L, Feng X, Wang Y, Hu M, Pan T, et al. Moderate hypothermic circulatory arrest with antegrade cerebral perfusion for rapid total arch replacement in acute type A aortic dissection. Thorac Cardiovasc Surg. 2016;64:124-32.
38. Shrestha M, Kaufeld T, Beckmann E, Fleissner F, Umminger J, Abd Alhadi F, et al. Total aortic arch replacement with a novel 4-branched frozen elephant trunk prosthesis: single-center results of the first 100 patients. J Thorac Cardiovasc Surg. 2016;152:148-59.e1.

39. Aalaei-Andabili SH, Scali S, Klodell C, Lee T, Hess P, Martin T, et al. Outcomes of antegrade stent graft deployment during hybrid aortic arch repair. Ann Thorac Surg. 2017;104:538-44.

40. Chen L, Qi RD, Liu W, Li CN, Zhang N, Zhu JM, et al. Repair of complicated chronic type B dissection with distal aortic arch involvement using left subclavian artery transposition with implantation of a stented elephant trunk. Thorac Cardiovasc Surg. 2017;65:99-104.

41. Hu X, Wang Z, Ren Z, Hu R, Wu H. Simplified total aortic arch replacement with an in situ stent graft fenestration technique for acute type A aortic dissection. J Vasc Surg. 2017;66:711-7.

42. Preventza O, Coselli JS, Mayor J, Simpson K, Carillo J, Price MD, et al. The stent is not to blame: lessons learned with a simplified US version of the frozen elephant trunk. Ann Thorac Surg. 2017;104:1456-63.

43. Verhoye JP, Belhaj Soulami R, Fouquet O, Ruggieri VG, Kaladji A, Tomasi J, et al. Elective frozen elephant trunk procedure using the E-Vita Open Plus prosthesis in 94 patients: a multicentre French registry. Eur J Cardiothorac Surg. 2017:52:733-9.

44. Koizumi S, Nagasawa A, Koyama T. Total aortic arch replacement using frozen elephant trunk technique with J Graft Open Stent Graft for distal aortic arch aneurysm. Gen Thorac Cardiovasc Surg. 2018;66:91-4.

45. Kreibich M, Berger T, Morlock J, Kondov S, Scheumann J, Kari FA, et al. The frozen elephant trunk technique for the treatment of acute complicated type B aortic dissection. Eur J Cardiothorac Surg. 2018 53:525-30.

46. Ma M, Feng X, Wang J, Dong Y, Chen T, Liu L, et al. Acute type I aortic dissection: a propensity-matched comparison of elephant trunk and arch debranching repairs. Interact Cardiovasc Thorac Surg. 2018;26:183-9.

47. Roselli EE, Idrees JJ, Bakaeen FG, Tong MZ, Soltesz EG, Mick S, et al. Evolution of simplified frozen elephant trunk repair for acute DeBakey type I dissection: midterm outcomes. Ann Thorac Surg. 2018;105:749-55.

48. Borst HG, Walterbusch G, Schaps D. Extensive aortic replacement using "elephant trunk" prosthesis. Thorac Cardiovasc Surg. 1983;31: 37-40.

49. Kato M, Ohnishi K, Kaneko M, Ueda T, Kishi D, Mizushima T, et al. New graftimplanting method for thoracic aortic aneurysm or dissection with a stented graft. Circulation. 1996;94:II188-93.

50. Hanif H, Dubois L, Ouzounian M, Peterson MD, El-Hamamsy I, Dagenais F, et al. Aortic arch reconstructive surgery with conventional techniques vs frozen elephant trunk: a systematic review and meta-analysis. Can J Cardiol. 2018;34: 262-73.

51. Tian DH, Wan B, Di Eusanio M, Black D, Yan TD. A systematic review and meta-analysis on the safety and efficacy of the frozen elephant trunk technique in aortic arch surgery. Ann Cardiothorac Surg. 2013;2:581-91.

52. Etz CD, Weigang E, Hartert M, Lonn L, Mestres CA, Di Bartolomeo R, et al Contemporary spinal cord protection during thoracic and thoracoabdominal aortic surgery and endovascular aortic repair: a position paper of the vascular domain of the European Association for Cardio-Thoracic Surgery. Eur J Cardiothorac Surg. 2015;47:943-57.

53. Pacini D, Tsagakis K, Jakob H, Mestres CA, Armaro A, Weiss G, et al. The frozen elephant trunk for the treatment of chronic dissection of the thoracic aorta: a multicenter experience. Ann Thorac Surg. 2011;92: 1663-70.

54. Coselli JS, LeMaire SA, Preventza O, de la Cruz KI, Cooley DA, Price MD, et al. Outcomes of 3309 thoracoabdominal aortic aneurysm repairs. J Thorac Cardiovasc Surg. 2016;151:1323-37.

Key Words: frozen elephant trunk, aortic arch, aortic dissection, paraplegia, spinal cord deficit 


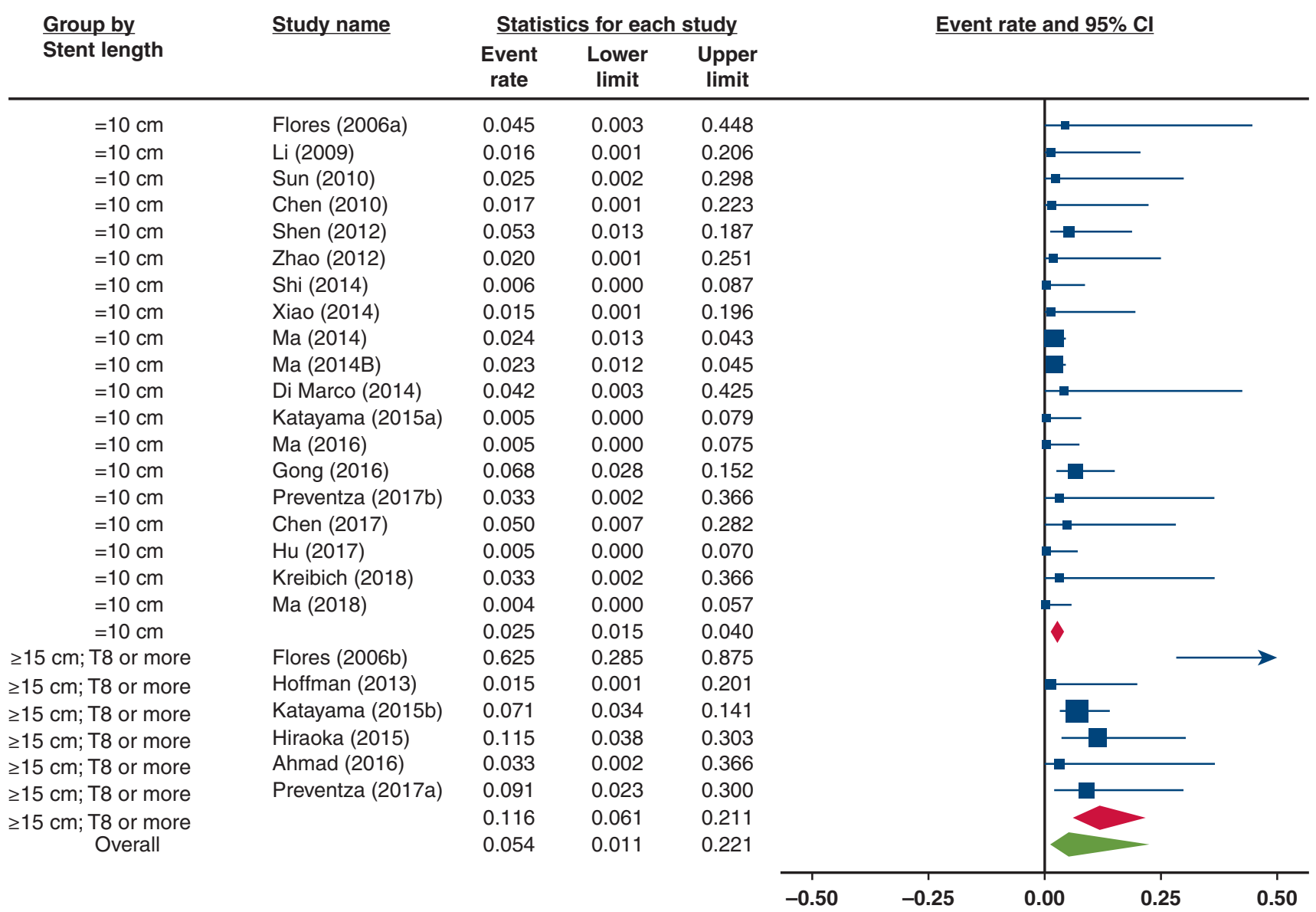

FIGURE E1. Subgroup analysis: SCI in patients treated with stents $15 \mathrm{~cm}$ or greater or spinal coverage T8 or beyond versus patients with 10 -cm stent length. In the Forest plot, the estimate of the event rate of each study corresponds to the middle of the blue squares, and the horizontal line through the squares shows the $95 \%$ CI. The subgroup pooled event rates are represented by the middle of the solid red diamonds, with the width of the diamonds representing the $95 \% \mathrm{CI}$. The summary pooled event rate is represented by the middle of the solid green diamond with the width of the diamond representing the $95 \% \mathrm{CI}$ and indicates that $11.6 \%$ (95\% CI, 6.1-21.1) of the patients with stent length $15 \mathrm{~cm}$ or greater or coverage T8 or beyond had a spinal cord ischemic event after FET, compared with $2.5 \%(95 \%$ CI, 1.5-4.0) of the patients with stent length $10 \mathrm{~cm}(P<.001)$. Note: For reference 42 (Preventza 2017$)$, the authors provided additional information not included in the publication. Among the 37 patients, the stent lengths used were $10 \mathrm{~cm}(\mathrm{n}=14), 12.5 \mathrm{~cm}(\mathrm{n}=1)$, and $15 \mathrm{~cm}(\mathrm{n}=22)$. SCI occurred in 2 patients with $15-\mathrm{cm}$ stents. $C I$, Confidence interval. 


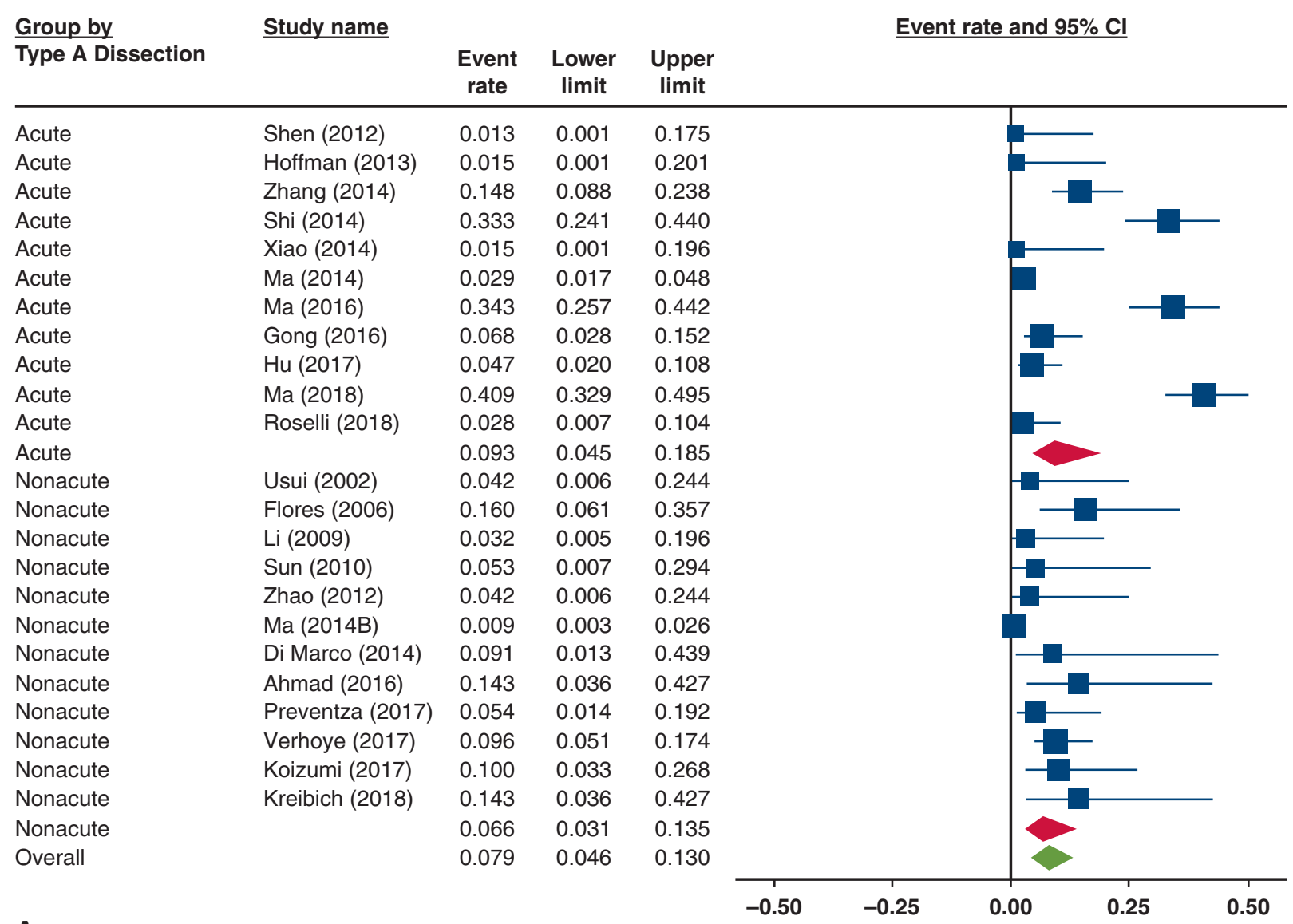

\section{A}

FIGURE E2. Subgroup analysis: Outcomes in patients treated for acute type A dissection versus nonacute type A dissection and aneurysm. For these 2 subgroups, respectively, Forest plots show the post-FET event rates for (A) overall, persistent, or transient stroke (9.3\% [95\% CI, 4.5-18.5]) vs 6.6\% [95\% CI, 3.1-13.5], $P=.51$ ); (B) spinal cord injury, including persistent and transient paralysis, paraplegia, and paraparesis $(2.4 \%$ [95\% CI, 1.3-4.2] vs 5.2\% [95\% CI, 3.1-8.5], $P=.05)$; and (C) overall, operative, 30-day, or in-hospital mortality (9.2\% [95\% CI, 6.9-12.4] vs 7.6\% [95\% CI, 4.9-11.4], $P=.46)$. The estimate of the event rate of each study corresponds to the middle of the blue squares, and the horizontal line through the squares shows the $95 \%$ CI. The subgroup pooled event rates are represented by the middle of the solid red diamonds, with the width of the diamonds representing the $95 \%$ CI. The summary pooled event rate is represented by the middle of the solid green diamond, with the width of the diamond representing the $95 \%$ CI. CI, Confidence interval. 


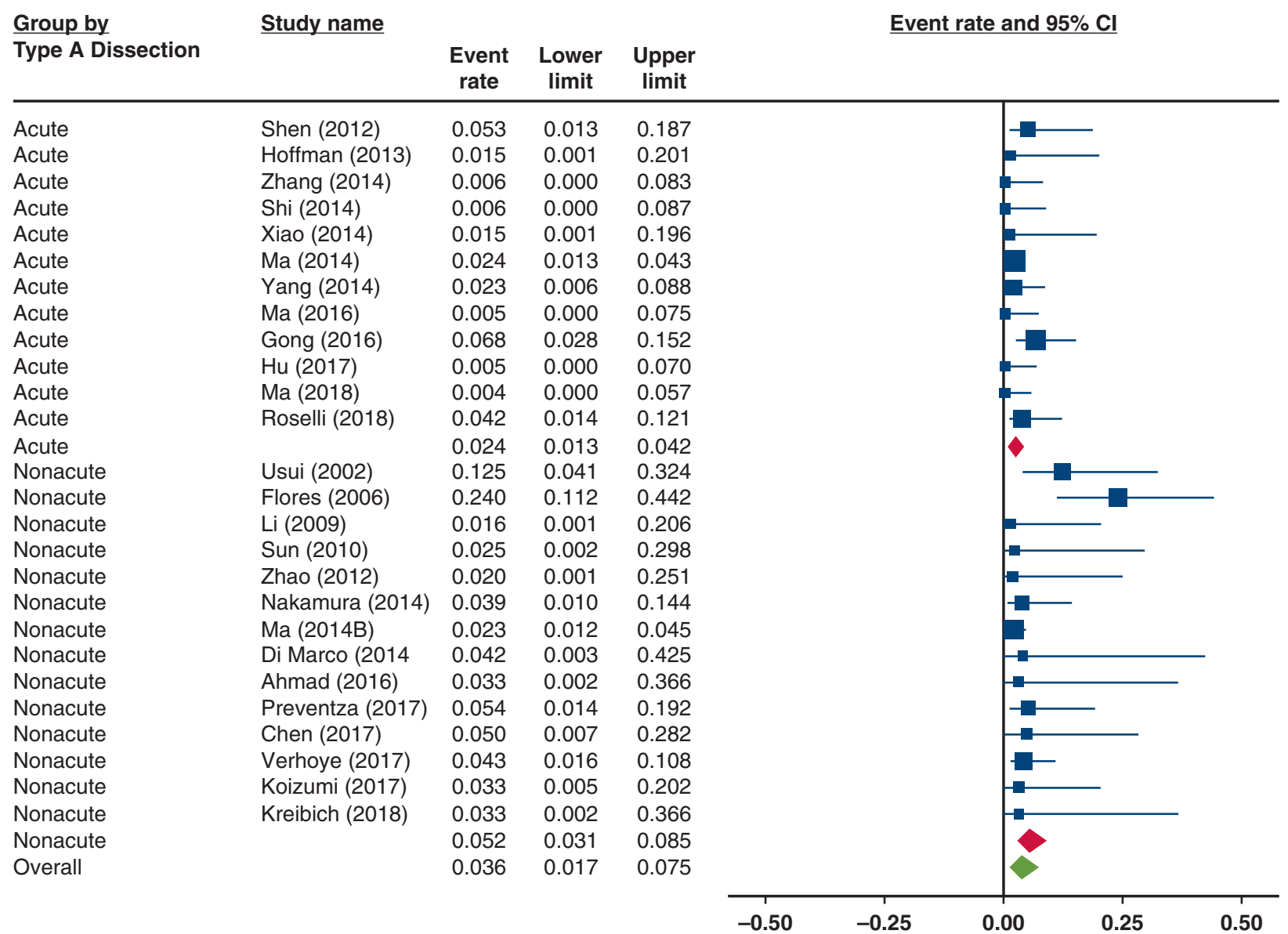

B

FIGURE E2. Continued 
Group by

Type A Dissection

Acute

Acute

Acute

Acute

Acute

Acute

Acute

Acute

Acute

Acute

Acute

Acute

Acute

Nonacute

Nonacute

Nonacute

Nonacute

Nonacute

Nonacute

Nonacute

Nonacute

Nonacute

Nonacute

Nonacute

Nonacute

Nonacute

Nonacute

Overall

C
Study name

\begin{tabular}{lccc} 
& $\begin{array}{c}\text { Event } \\
\text { rate }\end{array}$ & $\begin{array}{c}\text { Lower } \\
\text { limit }\end{array}$ & $\begin{array}{c}\text { Uppe } \\
\text { limit }\end{array}$ \\
\hline Shen (2012) & 0.079 & 0.026 & 0.218 \\
Hoffman (2013) & 0.031 & 0.004 & 0.191 \\
Zhang (2014) & 0.057 & 0.024 & 0.129 \\
Shi (2014) & 0.060 & 0.025 & 0.135 \\
Xiao (2014) & 0.182 & 0.084 & 0.350 \\
Ma (2014) & 0.081 & 0.059 & 0.110 \\
Yang (2014) & 0.058 & 0.024 & 0.132 \\
Ma (2016) & 0.172 & 0.110 & 0.259 \\
Gong (2016) & 0.122 & 0.065 & 0.218 \\
Hu (2017) & 0.075 & 0.038 & 0.144 \\
Ma (2018) & 0.144 & 0.094 & 0.215 \\
Roselli (2018) & 0.042 & 0.014 & 0.121 \\
& 0.092 & 0.068 & 0.124 \\
Usui (2002) & 0.020 & 0.001 & 0.251 \\
Flores (2006) & 0.120 & 0.039 & 0.313 \\
Li (2009) & 0.065 & 0.016 & 0.224 \\
Sun (2010) & 0.053 & 0.007 & 0.294 \\
Zhao (2012) & 0.042 & 0.006 & 0.244 \\
Ma (2014B) & 0.043 & 0.026 & 0.070 \\
Di Marco (2014) & 0.042 & 0.003 & 0.425 \\
Ahmad (2016) & 0.033 & 0.002 & 0.366 \\
Preventza (2017) & 0.216 & 0.112 & 0.376 \\
Chen (2017) & 0.050 & 0.007 & 0.282 \\
Verhoye (2017) & 0.117 & 0.066 & 0.199 \\
Koizumi (2017) & 0.016 & 0.001 & 0.211 \\
Kreibich (2018) & 0.033 & 0.002 & 0.366 \\
& 0.076 & 0.049 & 0.114 \\
& 0.086 & 0.067 & 0.110 \\
& & &
\end{tabular}

Event rate and $95 \% \mathrm{Cl}$

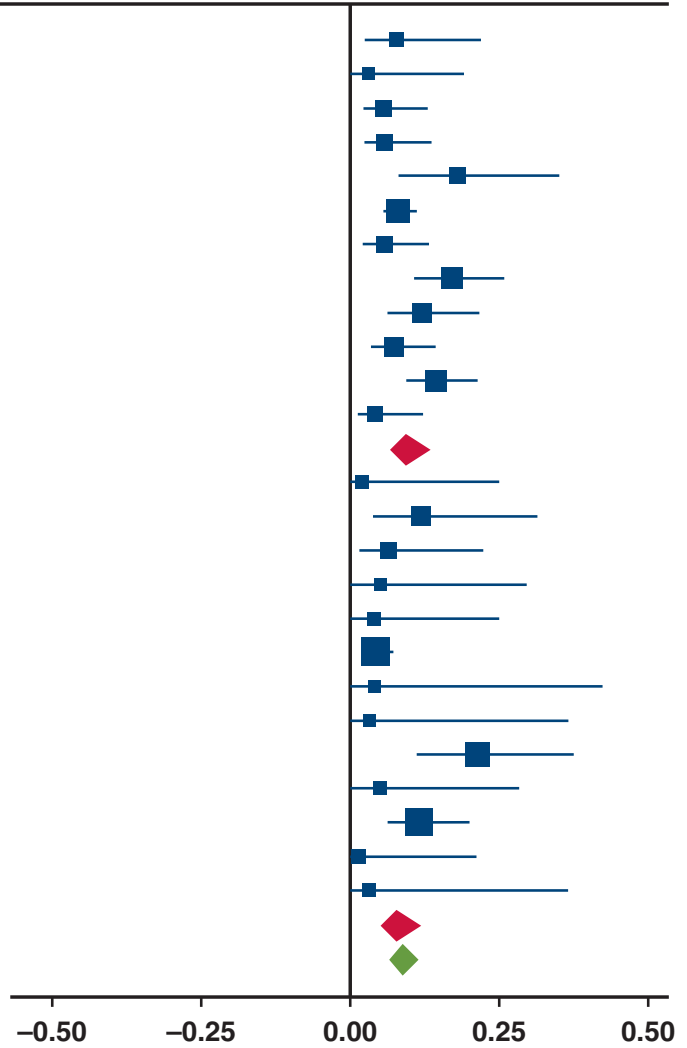

FIGURE E2. Continued 